\title{
ע Linguistic AND SOCIOLINGUISTIC ASPECTS OF VARIATION IN THE EASTERN CAPE: COMPLEXITIES OF XHOSA LANGUAGE USE
}

\author{
Eva-Marie Bloom Ström \\ University of Gothenburg
}

\begin{abstract}
The overall goal of this paper is to explore morphosyntactic variation in the Xhosa dialect cluster. It presents the results of a micro-variation project in which linguistic diversity of the Eastern Cape of South Africa is examined. It shows that regional variation in the Xhosa dialect cluster is minimal and that many older forms and sounds that have previously been reported on are no longer in use. With a specific focus on morphosyntactic variation, the paper gives examples from a corpus of recorded, transcribed and glossed speech collected across the Eastern Cape. It is argued that spontaneous speech is crucial in analysing morpho-syntactic variation when it is on a finegrained, intralinguistic level. The paper gives a detailed overview of previous publications on the dialects of the area and relates this to current findings based on the recordings. It is shown that the decline in dialectal differences does not correlate with a decrease in the linguistic identity which is connected to separate clans and kingdoms. The dwindling use of regional variants is explained by a long history of personal mobility, standardization and schooling. The primary contribution of the paper is to show that regional or dialectal variation on all linguistic levels is synchronically very fine-grained. It also contributes to our understanding of the linguistic complexities of the Nguni subgroup of Bantu languages. It is concluded that the differences reportedly experienced between standard Xhosa and the language spoken at home are not due to regional variation, and that their causes should be sought elsewhere, such as perhaps in an outdated standard.
\end{abstract}

\section{INTRODUCTION}

Attitudes to language loss by speakers of endangered languages are not uniform but vary widely, even within the same community (Mithun 1998). Some speakers of endangered languages experience a great sense of loss when their varieties are disappearing. Another scenario is that in which speakers express that speaking their variety stigmatizes them and that they prefer to switch to the majority language (for an example, see Ström 2009). In both cases, the reduction of use of the endangered variety is a fact, but speakers react differently to it. This paper presents a rather different situation, in which there is a strong linguistic identity, although such an identity - shown by the results of this study - is based on other aspects than differences in language use. It shows that regional dialectal traits, which are assumed to have thrived among separate strong clans

Volume 6 (2018), pp. 90-120

DOI $10.23993 /$ store. 75138

Licensed under Creative Commons Attribution 3.0 License.

ISSN: 2323-5209

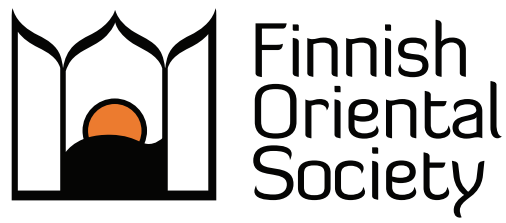


and kingdoms of the Xhosa (Slabbert \& Finlayson 1998), can now be concluded to have been heavily influenced by standard Xhosa. ${ }^{1}$

The paper has the following aims: first, to determine the nature and extent of morphosyntactic variation in the Xhosa language cluster. As will be shown in Section 2, the variation that can be detected in natural spoken Xhosa is on a very fine level and does not hinder mutual intelligibility. This confirms certain previous reports that dialects are mostly heard among older people or hardly at all (Cantrell 1974; Pahl 1983; Jokweni 1995). Although others have claimed that regional variation is considerable and that, had history progressed differently, speech forms such as those of the Mpondo, Bhaca and Hlubi could have been distinct languages under the Nguni cluster (Nyamende 1994; Gxilishe 1996), such claims appear to be based on data from older sources.

There is almost complete mutual intelligibility between speakers of different areas of the Eastern Cape and speakers of standard Xhosa (such as, for example, the speakers who worked with me on this project as assistants or transcribers). If there is any lack of understanding on their part, it is almost exclusively caused by the use of lexemes that they are not aware of. However, speakers often claim that their variety is radically different from the standard Xhosa language. The second aim of the paper is to explain this intriguing sociolinguistic situation, a strong linguistic identity that is not matched by real differences in language use. It will be argued in Section 4 that this strong linguistic identity has its origin in a long history of separate clans and kingdoms. The findings of this paper will be set in relation to the variation reported on in previous publications, and then the lack of real variation in the data collected for this study is argued to be evidence of language reduction, which can be understood by considering a number of socio-historic factors.

The paper also has a methodological aim. Comparative linguistic research in the Bantu linguistic field often takes a certain morphosyntactic construction as its point of departure and compares its form and use across the language family. In recent years, there is increased interest in comparisons on a more intralinguistic level (see Bloom Ström \& Petzell in press). Such a micro-variation approach was chosen for the present study. ${ }^{2}$ For this specific project, considering the (socio-)linguistic situation of the area, it was decided to base the analysis on recordings of natural language use, combined with limited elicitation. This will be further outlined and argued in Section 3. The paper ends with a summary and conclusions in Section 5.

Before addressing these aims, a short background will be provided for Xhosa as a Bantu language within the Nguni subgroup, including the language situation of the Eastern Cape and the standardization of Xhosa.

\footnotetext{
1 Language names in the Bantu language family are indicated with a prefix in the different languages. The Xhosa language, for example, is referred to as isiXhosa and its people as amaXhosa. I use these names as in English, without the prefixes, in this paper.

2 The research project "Morphosyntactic Variation in the Dialects of Xhosa" (2015-2017) was funded by the Swedish Research Council, with additional support for fieldwork and corpus development by the following foundations: Åke Wiberg, Birgit and Gad Rausing, Kungliga Vetenskapsakademien, Gunvor and Josef Anér, Knut and Alice Wallenberg, Wilhelm and Martina Lundgren, and Magnus Bergvall. I am thankful to them as well as to the host of my post-doctoral study, the Department of English Language and Linguistics at Rhodes University, Makhanda (formerly Grahamstown). Most importantly, I thank the speakers who took part in this study and contributed to interviews and recordings.
} 


\subsection{Xhosa within Nguni}

Xhosa is a language of the Bantu language family, within the Nguni subgroup. This subgroup is also referred to as S40 in the classification by Guthrie (1967-1971). In order to understand the intralinguistic variation of the language, we first need to consider its position within this subgroup.

The Nguni languages are relatively tightly knit, and especially Zulu and Xhosa are closely related, with a high degree of mutual intelligibility. According to Jokweni (1995: 4), the Nguni languages distinguish themselves through lexical items, tonal patterns and phonemes. Morphosyntactic differences are, for example, found in the formation of copulatives and complex verb forms (Doke 1954). Systematic studies of morphosyntactic variation are scarce, however, and linguistic research, due to the many similarities, at times takes the whole Nguni group as the subject of study (e.g. van der Spuy 1993). Not surprisingly, harmonization of a Nguni written standard, to be used in formal situations, has been argued for (e.g. Alexander 1998). Such attempts to unify the languages have so far been rejected, and it has been claimed that this is due to the strong identities of the different Nguni people (Slabbert \& Finlayson 1998).

The Nguni group has been subdivided in different ways. There is often a two-way distinction in the literature between the so-called Zunda and Tekeza languages. This division is mainly based on a phonological difference called ukutekeza or ukutekela. Certain languages, notably Swati, use a / $/$ / where the Zunda languages (for example, Zulu and Xhosa) have / $\mathrm{z} /$ (Gowlett 2003). Thus, for instance, the Bhaca, belonging to the Tekeza group, say umfati rather than umfazi 'woman' (Pahl 1983; see also Section 4.1.3). Others classify Xhosa and Zulu as independent languages, with Swati constituting a separate branch together with the regional varieties Bhaca, Hlubi and Phuthi as independent Tekeza varieties (Doke 1954) or as dialects of Swati (Lewis et al. 2014). Southern and Northern South African Ndebele are also considered Tekeza varieties, as is Lala (Gowlett 2003) and Ntlangwini (Louw \& Jubase 1963; Pahl 1983). For illustration, the classifications of Lewis et al. (2014) and Gowlett (2003) are given in the following Figure 1. In this paper, however, I make no claims regarding the classification of Nguni or any of its varieties.
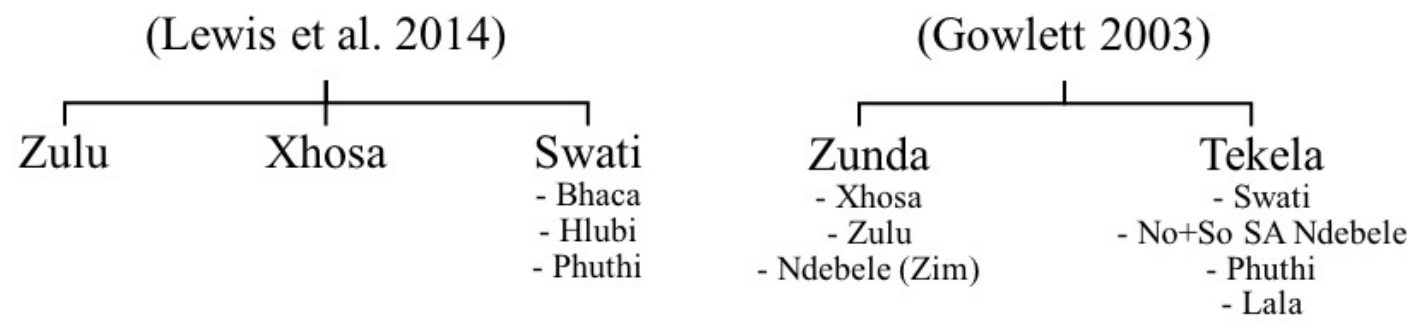

Figure 1 Two classifications of Nguni 
As pointed out by Cassimjee (1998: 1), the status of Bhaca and Hlubi as independent and identifiable languages is a matter requiring research, and Maho (2003) adds Bhaca S402, Hlubi S403 and Phuthi S404 directly under the Nguni group, as the closest affinity within the group is uncertain. Apart from the phonological distinction mentioned above, "there is little or no evidence to support the idea that Tekeza represents a linguistic subgroup" (Herbert \& Bailey 2002: 62-63). Bhaca is also at times listed as a dialect of Xhosa (Nordhoff et al. 2013). In conclusion, the lower-level groupings in Nguni are highly uncertain. The Xhosa varieties considered in this paper could in some cases also be considered as varieties of Zulu or Swati. Mpondo, for example, is said to lie somewhere between Zulu and Xhosa, bringing it closer to Xhosa due to education in the standard (Cantrell 1974: 10).

The speech forms of some of the clans now referred to as Xhosa served as a base for the standard; namely, these were the varieties spoken around Lovedale, where missionaries started to write the language for the first time (Doke 1954; Louw \& Jubase 1963; Claughton 1992; Nyamende 1994). These were the $\mathrm{Ngqika}^{3}$ and Ndlambe people, also jointly referred to as Rharhabe, ${ }^{4}$ as well as the closely related Gcaleka (Doke 1954: 23). The Gcaleka and Rharhabe are the peoples generally referred to as Xhosa in the narrow sense, or the Tshiwo Xhosa, referring to people decending from the paramount chief Tshiwo, who lived around 1700 (Pahl et al. 1989). The present orthography, based on these speech form, is the linguistic variety taught in schools in which all school materials are written. In the present paper, the language name Xhosa is not used in this narrow sense but in a wider one (Claughton 1992: 4-5), referring to speakers of any variety of the language cluster. It should be noted that it is considered incorrect by the population in the northern part of the Eastern Cape to refer to them and their language as Xhosa. They have other ethnic and linguistic identities that are traditionally referred to as dialects of Xhosa. For ease of reference, I will follow the academic tradition and refer to Xhosa as an overarching language/dialect cluster.

\section{MORPHOSYNTACTIC VARIATION IN PRESENT-DAY XHOSA}

The main aim of this paper - to determine to what extent there is morphosyntactic variation in Xhosa and how this variation manifests itself - is adressed in this section. There are several reasons for the study of morphosyntactic variation presented in this paper. As the background in Section 1.1 shows, the precise relationship between the Nguni varieties - those considered languages as well as those considered dialects - is unclear. With this in mind, it is interesting to find apparently contradicting reports about their similarities as well as their differences. Previous reports on variation in Xhosa are almost exclusively based on phonology and lexicon, and some of the phonological variables are still relevant to this day. Although revealing these differences was not the primary goal of this paper, the variables encountered will be noted in Section 4, in which previous publications on variation in Xhosa are discussed. The focus on morphosyntax in this paper is therefore motivated by the lack of studies on morphosyntactic variation in Xhosa. If there are differences between regional varieties, and these differences are limited in phonology and lexicon, then they can possibly be found in morphosyntax. An additional motivation for this study came from recent reports of differences between the standard taught in schools and the language spoken at home, as

3 The latter is sometimes referred to as Gaika, which is an English version of the name (Jokweni 1995).

4 Sometimes written Rhatabe (de Jager 1964). 
further outlined in Section 3.1. Thus, this study also aims to contribute to our knowledge of how the home language differs from the standard.

It was found that the best way to achieve this goal was to base the linguistic analysis on recordings of natural spoken language, at times with follow-up questions in elicitation. This will be discussed and argued for in Section 3.1, while details on the corpus resulting from data collection in different locations in the Eastern Cape are given in Section 3.2.

The remainder of this section presents the relevant results and examples of morphosyntactic variation found in the corpus. ${ }^{5}$ While the recordings have been transcribed and partly glossed, the examples in this section are presented as snippets taken from the corpus. This is because their purpose here is to exemplify a certain grammatical construction. Details regarding age and sex are given in footnotes for each example, as well as speaker's name. ${ }^{6}$

Before presenting the relevant examples illustrating morphosyntactic variation, a few examples of phonological and lexical differences that were corroborated during data collection are given here: for instance, a speaker from Nqileni (see the map on page 107) says itshumi "ten" ${ }^{17}$ and igutsha 'sheep' rather than standard ishumi and igusha: ${ }^{8}$

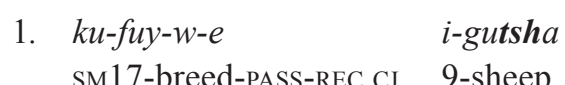

sheep

'Sheep were being kept.' [BU160401D_c] ${ }^{9}$

However, several of the expected phonological differences, such as the $u k u d o n d r o z a$ of the Mpondo speakers, is very rarely heard. Ukudondroza refers to the use of the consonant combination $d r$, whereas standard Xhosa has $d$ (Pahl 1983). Differences in tone that have been noted in previous studies (Jokweni 1995; Cassimjee \& Kisseberth 1998) are expected to still play a role, but the establishment of such differences has not been attempted. Such lexical tone differences are in some cases also indicated in The Greater Dictionary of IsiXhosa (Pahl et al. 1989-2006).

Other reported differences often concern lexicon. In the corpus, there are several words that sounded archaic to the young, standard-speaking transcribers. Some words are referred to as 'Zulu', by them as well as by the speakers themselves. An example is ikhafu 'food', which is isikhafu in noun class 7 in Zulu (Doke \& Vilakazi 1958):

\footnotetext{
5 Examples taken from the collection of spoken texts are coded by means of an abbreviation of the place name. $\mathrm{BU}=$ Bulungula, the village of Nqileni, also referred to as Bulungula, which is the name of the river flowing through this village on the coast of the Mbashe municipality. BLN=Baleni, a village in the Mbizana municipality in the north-east of the Eastern Cape. $G X=$ Gxulu, outside Mthatha. MTF=Mount Frere. PSJ=Port St. Johns. $\mathrm{STP}=$ Sterkspruit. This is followed by the date of the recording and, in this case, a letter D for dialogue. Other abbreviations are $\mathrm{M}$ for monologue and $\mathrm{O}$ for oral tradition or story. Elicited examples are coded with the initials of the speaker, the date and an E. Certain elicited examples are based on stimuli such as cartoon pictures, and they are coded with $\mathrm{S}$.

6 After receiving information about the purpose of the recordings, all speakers interviewed for this study have explicitly requested to be mentioned by name. It is their wish that their contributions to this research be made public. 7 BU160401D_d.

8 Texts in the corpus have been transcribed according to conventions based on Allwood et al. (2005), and some of these have been kept in the examples in this paper. Parentheses indicate that the vowel or some other element is not heard. A plus sign $(+)$ indicates that the word is not finished (self-correction or stuttering). Only elicited examples have been marked for tone (high tones marked with acute accent) and vowel length (with a colon).

9 Nolotovu Futu, male, 69 years.
} 
2. ku-phum-e i-khafu

SM17-come.out-SBJV 9-food

'(Then) there comes out food.' [GX150515M_b] ${ }^{10}$

In fact, the speaker of this example also uses the more standard $u k u d l a$ 'food' (in noun class 15) in the same monologue.

Turning to morphology and syntax, then, we find variation in the form of the non-verbal copulative, which is also used to introduce the agent of a passive verb. The copulative used by standard speakers in noun class 2 is $n g a-$, but in the northern part of the Eastern Cape we find $b a-$ :

3. in-kwenkwe i-khwel-e emthini, ya-w-a phantsi,

9-boy SM9-climb-REC.CJ LOC.tree SM.PST9-fall-FV down

ya-bon-w-a ba-bantu

SM.PST9-see-PASS-FV 2COP-2.people

'A boy has climbed the tree, he fell down, he was seen by people.' [SN150927S] $]^{11}$

This area is considered Mpondo and the speakers speak the Mpondo variety (see Section 4.1). Examples of $b a$ as a copulative in Mpondo are found in the literature, such as babam 'they are mine' instead of ngabam (Nomlomo 1993; Section 2.1). Other variants such as ngum or ngumi for the first-person copulative, where Xhosa would have ndim 'it is me', have not been encountered in the material collected so far.

Also, the copulative in the Bhaca variety is reported to be distinct from the standard (Jordan 1942). The expected form of the copulative with pronoun on the basis of Jordan (1942) is formed with a prefix $h$-. A similar copulative is reported for a variety of Zulu (Poulos \& Msimang 1998: 357). In the corpus we do indeed find examples, such as the following in noun class 2 :

4. ha-bo

2COP-2.PRO

'it is they' [MTF170609D_c] $]^{12}$

In the standard this would be ngabo. In the same recording, however, the same speaker also uses the standard form ndim 'it is me' where Bhaca, according to Jordan (1942), would have hum. We also find yinkwenkwe 'it is a boy', just like in the standard, instead of the reported variant form $h i$ - for noun class 9. Jordan (1942) gives hinja 'it is a dog' as an example (standard yinja). Arguably, this shows that speakers do not use the regional form in a consistent manner but that standard and regional variants are blended. I take this as a sign of decline in the use of such regional varieties.

Apart from these limited examples of the copulative, the variation encountered mainly concerns the verb phrase, and more specifically in verb forms that are originally combinations of more than one inflected verb. The recent past imperfective, for example, derives from the verb $u k u$-ba 'to be' in the recent past, contracted with the main verb. Example (5) shows the standard form in noun class 1 ebe-, including the subject marker:

10 Nozandla Nomdebevana, woman, 73 years.

11 Sikhuthele Chris Ncamani, male, 30 years. Baleni.

12 Princess Mamaduna Sigudu, female, 75 years. 
5. um-ntwana om-ncinci ebe-theth-a $\quad$ kakhulu
1-child 1AC-small SM.IPFv1.REC-speak-Fv a.lot
'The small child was talking a lot.' (Davey 1973: 83)

In fact, the form ebe- is an assimilated form of $u b e$-, where $u$ - is the subject marker of noun class 1. The variation between ebe- and ube- is long known (McLaren 1944), but the unassimilated form (ube-) is rarely used by young urban Xhosa speakers. ${ }^{13}$ In our data from rural areas, however, this form does also occur with young speakers:
6. ba-fik-e
e-lil-a
ube-qaqanj-el-w-a
kakhulu
SM.PST2-arrive-REC.CJ SM.PRT1-cry-FV
SM.IPFV1.REC-PASS $\backslash$ ache-APPL-PASS-FV
a.lot
$\begin{array}{llll}\text { li-dolo } & \text { elo } & \text { a-nzakel-e } & k u \text {-lo } \\ \text { 5COP-knee } & \text { 5DEM.MED } & \text { SM.SBJv1-hurt-SBJV } & \text { LOC-5DEM.PRX }\end{array}$

'He was crying when they came. He was being caused much pain by that knee which was hurt.' [BU151210S_a $]^{14}$

However, the verb form can also exibit the full two inflected verbs, whereby $u k u$ - $b a$ is inflected in the recent past, and the main verb occurs as a participial (Louw \& Jubase 1963). This pattern is rare, according to Davey (1973), and confirmed by very few occurences in the corpus data, such as the following example (in fact with the same speaker as the example above):

7. ku-vel-e i-moto e-bomvu

SM17-appear-REC.CJ 9-car 9RC-red

$\begin{array}{lll}\boldsymbol{e} \text {-be } & \boldsymbol{i} \text {-si-z-a } & \text { ngasentla } \\ \text { SM.IPFV9-be.REC } & \text { SM.PRT9-PRT-come-FV } & \text { from.above }\end{array}$

'There appeared a red car coming from above.' [BU151210S_b $]^{15}$

Surprisingly, this speaker uses ebe- for noun class 9, rather than the expected ibe in the unreduced form following the standard. Whether this is a form that is used by others in the region or idiolectal variation is something I cannot answer at this point.

The kind of synchronic variation we see here in the verb phrase is expected from a grammaticalization perspective. Attrition is the gradual loss of semantic and phonological substance, also involving morphological degeneration (Lehmann 1985). Combined with this, syntactic constructions such as periphrastic forms can increasingly integrate into morphological paradigms. When there is a choice between different strategies at different levels of attrition and paradigmaticity, such as with compound verb constructions, this often feeds into linguistic change and moves along the same scales as grammaticalization (Lehmann 1985).

Apart from this variation in reduced/unreduced forms, there is also allomorphy in the recent past imperfective, as previously reported on in the literature (Nomlomo 1993). The prefix beoccurs as ze-for some speakers from Mbizana municipality in the north-east of Eastern Cape, home to the Mpondo people:

13 'Young urban Xhosa speakers' refers to the students at Rhodes University who have transcribed and glossed the recordings. They mainly come from urban centres such as Mthatha, Port Elizabeth, East London and, in one case, also Cape Town. Apart from being young and urban, they are, of course, also well educated. They are standard speakers insofar that they do not consider themselves as speaking any dialectal variant of Xhosa.

14 Ntombifikile Futu, female, 29 years.

15 Ntombifikile Futu, female, 29 years. 
8. si-ba+ba-fana ze-nd(i)-cing-a (uku)ba

... 2-young.men ze.REC-SM.IPFV1SG-think-FV that

$s a-s i+s a-s i-b a-n e$

... SM.PST1PL-IPFV1PL-2-four

'we are, young men I think we were, we were four' [BLN150924D_b] $]^{16}$

This form is interesting, as possibly it is not from ukuba but has its origin in ukuza 'to come'. The grammaticalization from 'to come' to a Tense Aspect Mood (TAM) with past reference is not uncommon in the languages of the world (Bybee et al. 1994: 56). However, it is unusual from a Bantu persective (Nurse 2008; Petzell in press). According to Nomlomo (1993), Mbadi (1956) reports this allomorphy as characterizing Mpondomise and gives a few examples, such as zesithetha instead of the standard besithetha 'we were talking'. The allomorph does not occur anywhere else in the corpus. Although this could be a coincidence, it can at least be concluded that it is not a frequently occurring form. Younger speakers in the same village do not use this form of the recent past imperfective. For this reason, I propose that the form with $z e$-is a remnant of earlier geographical variation. With the younger speakers, however, we find another kind of allomorphy:
9. na-le nto be-yi-s-enzek-a izolo
CONN-9DEM.PRX 9.thing be.REC-SM.IPFV9-PRT-happen-FV yesterday
'...of this thing that happened yesterday' [BLN150925D_c] ${ }^{17}$

Subject markers of the structure (N)CV take a form be-SM in the recent past imperfective in Xhosa. Subject markers consisting of a vowel only, on the other hand, generally take a form with the subject marker and a contracted form of be plus the verb, such as ube- in Example (6). As the subject marker of noun class 9 is the vowel $i$-, the expected standard form of the verb in Example (9) is ibisenzeka 'it happened'. The form beyisenzeka is accepted and a known variant according to my research assistant ${ }^{18}$ but not described in the literature. There Mpondo is said to always contract certain forms that can be still periphrastic in Xhosa. For example, Mpondo has bendibona where Xhosa has ndibe ndibona or bendibona (Cantrell 1974) in the recent past imperfective. The uncontracted form of the recent past imperfective is indeed not found in the data from this area. The contracted form is also formed differently, as seen in Example (9).

The infinitive in auxiliary constructions also appears to be at different levels of attrition. For example, the whole infinitive prefix (augment and noun class prefix) can be dropped:

$$
\begin{aligned}
& \text { 10. u-fun-(a) ndi-zek-a } \\
& \text { SM1-want-FV OM1sG-marry-FV } \\
& \text { 'He wants to marry me.' [BU160401D_d] }{ }^{19}
\end{aligned}
$$

Here, the standard would have ufun (a) ukundizeka. Omission of the prefixes, such as in 10, is not accepted by younger consultants (see footnote 13) who speak the standard variety.

In another example, only the infinitive augment $u$-is used on the infinitive, and the noun class prefix $k u$ - is omitted:

\footnotetext{
16 Male, 50 years.

17 Sikhuthele Chris Ncamani, male, 30 years.

18 Onelisa Mcimbi. However, this is not a variant that she herself would use.

19 Nowayitele Futu, female, 65 years.
} 


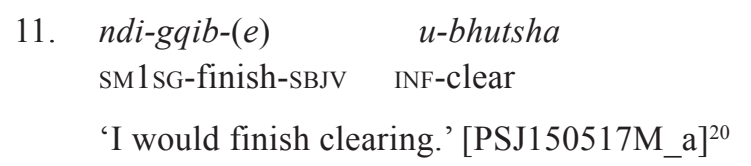

The infinitive prefix is omitted in the future in the Sterkspruit area, home to the Hlubi, as also pointed out by Pahl (1983: 264). The standard would have uzokusenga or uzakusenga in the following example:

12. $u-z a-\operatorname{seng} a$

SM2SG-FUT-milk

'You will milk.' [STP160430D_c] $]^{21}$

Infinitives are liable to show variation cross-linguistically, and there is a connection with grammaticalization. Variation in the form of the infinitive is often noted in other dialect projects, such as for Swiss German (Bucheli \& Glaser 2002: 47).

Apart from this, there is also some variation in relative constructions. One example is the omission of the relative suffix $-y o$ where it would be expected in the standard. The relative clause suffix - yo in Xhosa (and other Nguni languages) is often omitted when an adjunct, object or some other complement follows, but usually not when the predicate is phrase-final (Zeller 2004), that is, when the verb is independent or when there is predicate focus. In the recordings from the Sterkspruit area, all speakers leave out the relative suffix in the relevant contexts:

13. e-zi-nga-dl-iw-a

10RC-SM10-NEG-eat-PASS-FV

'That are not eaten (ref. to noun in class 10).' [STP160430D_c $]^{22}$

There is also variation in the form of the relative suffix. The Bhaca claim to speak a variety close to Swati, and indeed the variety does have many phonological characteristics in common with it (see Section 4.1.3). Also, the relative suffix in Bhaca is $-k o$, which is the same in Swati:

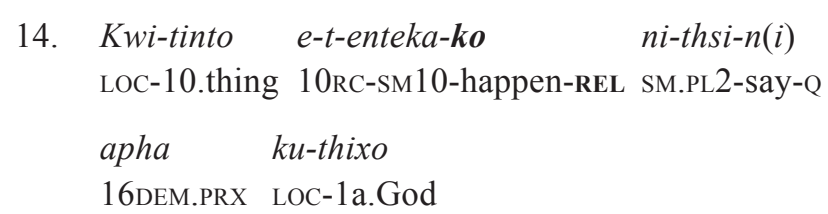

'What do you (pl) say here to God about the things that are happening?' [MTF170609D_i]

In conclusion, the project established a number of minor differences in the use of morphosyntactic constructions. We find variation in the copulative, as well as in certain complex TAMs that can be assumed to be in different stages of grammaticalization. I consider these as initial indications of variation that need further investigation. I have shown that the still limited corpus of natural speech is useful in establishing which constructions in the language are prone to variation (see the discussion in Section 3.1). The distribution of such morphosyntactic variables can reveal patterns of innovation and change in the language (see Bucheli \& Glaser 2002). Solid analysis of this variation should, of course, be based on "multiple texts collected from many speakers, so

20 Sibabini, male, 55 years.

21 Freshman Mehlomakhulu, male, 57 years.

22 Freshman Mehlomakhulu, male, 57 years. 
that conclusions are not influenced by a few speakers' idiosyncracies" (Reppen et al. 2002: vii). When working with lesser described languages, such texts are not always available, as in the case of Xhosa. This means it is necessary to start from scratch in building a corpus of texts. The methodological choices made during the project to deal with these challenges are the topic of the next section. Along with the patterns of phonological differences found in the region, the variation described in the current section will be further discussed in Section 4.

\section{ESTABLISHING VARIATION IN CLOSELY RELATED SPEECH FORMS}

In this section, I discuss the challenges in establishing variation within an area of closely related speech forms, particularly where there are scarce previous reports of such variation and where in fact the standard is also relatively undescribed. It will be argued in Secton 3.1 that an approach based on analysis of natural speech is needed before elicitation on a wider scale can be used to establish any geographical or other patterns. Due to this, a corpus was developed. Details about the corpus and its contents are provided in Section 3.2.

\subsection{Micro-variation in a Bantu dialect cluster}

The Bantu language family lends itself well to comparative linguistic research. The languages are typologically similar and share many aspects of their core grammar, such as the noun class system and the agglutinative nature of the verb phrase. At the same time, they also differ in a myriad of ways. The interest in comparing these languages in relation to certain grammatical constructions is increasing (see Bloom Ström \& Petzell in press; Marten et al. in press for overviews). Also, there is more interest in narrow geographical areas, as, for example, the Kikongo dialect cluster (de Kind et al. 2015; Dom \& Bostoen 2015) and the Greater Ruvu Bantu languages (Petzell \& Hammarström 2013). Inspired by these developments, as well as by micro-variation research in the European languages (Barbiers et al. 2002; Kortmann 2005; Poletto \& Benincà 2007; Johannessen et al. 2009; Bucheli Berger et al. 2012), this project set out to explore variation on a very fine scale (i.e. on varieties considered dialects of the same language).

Micro-variation here refers to the study and analysis of morphosyntactic variables of nonstandard varieties of language (Barbiers \& Cornips 2002). The addition of data on minute intralinguistic variation benefits the study of typology (Bucheli \& Glaser 2002; Kortmann 2002 ; 2004) but also improves the empirical basis for conclusions drawn in linguistic theory (Kortmann 2002). Micro-variation studies can help us understand how grammatical systems can differ and how these differences came about (Zanuttini \& Horn 2014). As a continuation of more traditional dialect research, focus is on morphosyntax.

Xhosa was selected as an excellent candidate for such a study within the Bantu group. There are several reasons for this. First, I aimed for an area in which linguistic differences would be on a fine-grained level, as motivated by previous micro-variation studies. It is well known that zone S of the Bantu language family is relatively homogenous, with Sotho-Tswana (S30) and Nguni (S40) forming clusters within this zone (Doke 1954). Second, it is of course also desirable to find enough intralinguistic variation to analyse. Hence, I aimed at a language for which such variation had been reported. Moreover, there were recent indications - in connection with a project exploring the linguistics of literacy - that for speakers of Xhosa the standard language used in schools often differs considerably from the variety spoken in the home (de Vos \& van der Merwe 2014). Third, Xhosa was selected due to it being one of the few Bantu languages 
to be relatively well-studied, with a long history of linguistic description (e.g. Doke 1954; Louw \& Jubase 1963; Davey 1973; Pahl et al. 1989-2006; du Plessis \& Visser 1992).

However, it became increasingly clear during the preparations and start of the project that this historical tradition is maintained by very few linguistic scholars. Recent publications on aspects of the morphosyntactic and semantic structure of the language language include Carstens and Mletshe (2015); Gowlett and Dowling (2015); Carstens and Mletshe (2016); Andrason and Dlali (2017); Bloom Ström (2017); Mletshe (2017); and Savić (2017). One might expect a larger body of research and researchers for such a relatively big - and official - language. There are still many unexplored aspects of the grammar of Xhosa. Moreover, in general morphosyntactic variation has not been part of previous studies on Xhosa, and publications on regional dialects (see Section 4.1) mainly include phonological and lexical data.

Due to this limited knowledge of where to expect morphosyntactic variation, I decided to make use of recorded and transcribed natural speech, and the examples of variation presented in this paper were all discovered through analysis of that data. Initial elicitation interviews were not successful in determining any differences in morphosyntax. The drawbacks of (translation) elicitation - such as interference from the interview language, influence by prescriptiveness and interviewee fatigue - are well known (Chelliah 2001; Mithun 2001; Bowern 2008; Mosel 2011). This becomes especially evident when a language is underdescribed and elicitation alone would lead us to document only the categories of grammar that we expect to find and think of asking about (Mithun 2001). Moreover, the variety may have grammatical distinctions that the standard does not have. Translation elicitation often results in literal translations from the source language, especially in the case of closely related varieties. An example from outside the Bantu languages is the interference of standard German in the case of the Swiss German dialects (Bucheli \& Glaser 2002). Moreover, care needs to be taken regarding the contradictory status of the Xhosa varieties: on one hand, they lack prestige and people speaking dialects can be stigmatized (Gxilishe 1996); on the other, the important ethnonyms can lead to hypercorrection (an interviewed speaker will feel the need to use variants that emphasize the distinct nature of the variety).

Although elicitation can be useful in uncovering morphology and verbal conjugation, it is hard to go beyond this, especially when the structures elicited depend on particular discourse conditions (Bucheli \& Glaser 2002). In some cases, such as when evidentiality plays a role (Chelliah 2001), even verbal conjugation cannot be easily elicited. Therefore, while elicitation can be used to complement initial understanding of a grammatical construction and for checking gaps, the main data for analysis should come from naturally occurring examples (Mosel 2011). Such examples can also be encountered in spontaneous conversations occurring in connection with an elicitation event (Bucheli \& Glaser 2002).

When there is no or very little background knowledge of variation in a language, the choice of which morphosyntactic construction to elicit becomes rather arbitrary. One can choose an area in which variation is known to exist, in this case from a Bantu comparative perspective, such as the use of inversion constructions (Marten \& van der Wal 2014). One type of inversion construction involves default agreement (of locative noun class 17) with the verb, and the postverbal subject is non-topical. Some speakers of Xhosa allow this kind of subject inversion with transitive verbs, while others only accept it with intransitive verbs (du Plessis \& Visser 1992; Carstens \& Mletshe 2015). Other Bantu languages are more restrictive and only allow it with unaccusative verbs (Marten et al. 2007). Hence, it is a potential area for regional or other variation. However, it can be hard to draw conclusions from a speaker's grammaticality judgements. 
This became evident to me when a speaker accepted a phrase (in Example 15) with an optional object. At a following session much later, he rejected the construction as ungrammatical:

$$
\begin{array}{lll}
\text { 15. [*] kú-lé:q-é } & \text { abantwana } & \text { (ikati) } \\
\text { SM17-chase-REC.CJ } & \text { 2.children } & \text { 9.cat }
\end{array}
$$

'The CHILDREN were chasing (the cat).' [NH150505E] / [*NH150908E $]^{23}$

It is advisable to be careful when creating contexts during elicitation, as it is always difficult to know if the interviewee has followed the intended context in his or her own mind. Consultants can also take other elements of context for granted and not feel the need to mention these to the linguist (Chelliah 2001). However, it is hard to elicit syntactic properties through means of stimuli or other methods than translation when the aim is to get comparative data across varieties (Cornips 2002). Therefore, I opted for a cyclical approach.

Hence, a fair number of recordings in different locations were made. After a first transcription and translation made by a speaker of Xhosa, I worked with the texts together with the transcriber. The first transcriptions had often been "cleaned up" (Chelliah 2001) by filling in morphemes that the speaker on the recording had actually left out, or by unconsciously correcting the speaker. This, then, had to be undone and noted. During these sessions, I also had the opportunity to ask if the transcriber would have expressed things in the same way and, if not, how they would form the phrase in question. I also used phrases from the texts for transformational elicitation and grammaticality judgements. These sessions were also recorded.

Following this, I worked with a linguistically trained speaker, gradually achieving an interlinearized text and at the same time learning the language in order to be able to understand how the different parts of grammar interact and to be able to spot variation in how speakers express themselves (see Everett 2001; Mosel 2011). This was a long, cyclical process in which we discussed morphemes and meanings, came back to the recording, and then realized that the speaker had said something else. All elements in an interlinearized text have to be morphologically analysed (Himmelmann 1998), and this also includes ones that are not part of constructions specifically looked at and written about during a project. This process was aided by the available publications on different aspects of Xhosa, as outlined above, as well as by discussions with fellow linguists. ${ }^{24}$

It was only during the process of interlinearization that variation could be established. After identifying the areas in which there is variation, such as in the use of complex verb constructions discussed in Section 2, results like these can be used to determine how frequent they are and if there are geographical or other variables that determine their use.

Here, elicitation interviews can be used. The insights from the texts can be used to get enough examples of a certain construction, along with the different contexts in which it may appear. It is possible at this point to present the speaker with a range of sentences, paired with the discourse context, in order to get negative data and to check for borders of grammaticality (Matthewson 2004). In doing so, however, one should remember that grammaticality judgements based on questions from an interviewer can be hard to base an analysis on (Mosel 2011). In any case, an approach with questionnaires filled in by speakers, such as in large-scale

23 Nkosekaya Hlitane, male, 21 years. East London.

24 I would specifically like to thank Stefan Savić and other researchers working on Xhosa at the Department of

English Language and Linguistics at Rhodes University. 
European dialect projects (Cornips 2002), is likely to be problematic due to low literacy and education levels, as well as unfamiliarity with questionnaires. There is no agreed upon way to write the home variety, and influence of the standard writing system should be avoided.

In sum, I argue for a cyclical approach, starting out with the discovery of a certain construction in spoken language. Following this, the construction can be tested with speakers in elicitation whereby the context of the utterance is carefully described. In doing so, we can find out who accepts this construction and what their origin, age, gender and so on is. Thereafter, the different variants accepted by the speakers should be corroborated by use in actual language, in order to conclude in a more solid way that these variants form part of a certain variety, in order to truly understand the contexts in which they can be used and to find out how frequently they are used. In order to do this, a large, representative corpus is needed, something that is not easily achieved. The following section addresses this challenge.

\subsection{A corpus of spoken language}

To be able to find variation in natural language, a corpus was constructed of transcribed recordings. The approach was to record dialogues, monologues, narratives and other communicative events without immediate consideration of the descriptive linguistic aims of the project, thereby employing a documentalist approach (Himmelmann 1998). In this way, the corpus will hopefully be useful for a wider community of linguists and researchers from other disciplines, in addition to the speaker community itself (Himmelmann 1998). ${ }^{25}$

\subsubsection{Contents of the corpus}

The medium of communication included in the corpus is spoken language at different degrees of spontaneity, not written or signed (Himmelmann 1998). However, most events were recorded on video as well as audio, enabling analysis of non-verbal communication and assisting in an understanding of context and interactions. The challenges in attaining natural kinds of communicative events are well known (Himmelmann 1998). Real spontaneous speech is in conflict with a recording situation in which informed consent from the speakers is a must (Himmelmann 1998). My approach has been to get as many recordings as possible, so that speakers eventually become more at ease and spontaneous situations occur in between. Many recordings in the corpus were set up with an assistant asking questions (as few as possible), which the speakers (one or many) answer; these often developed into a discussion, or sometimes more of a monologue with personal stories. We made efforts to minimize the inevitable effect of the observer's paradox. In all of these cases, the presence of myself as well as a standard speaker assistant possibly led the interviewed speaker to use less variant forms, even though the speakers knew the aim of the interviews and our interest in dialectal variation. Such influence was hopefully less prevalent in recorded dialogues in which two or more speakers from the community were having a conversation. At times it was possible for the assistant to quietly leave the situation. As I was a foreigner in South Africa, the interviewees did not expect more than a very limited knowledge of the language on my part, and hence they did not adapt or simplify their

25 At present, the corpus consists of nine hours of recordings. Five hours of this are transcribed and 1.5 hours are interlinearized, comprising around 6000 tokens. This was done manually. The material is under preparation to be stored by the Resource Management Agency of the South African Centre for Digital Language Resources. 
speech for me to understand it. Therefore, I could keep an eye on the recording devices from a corner without interfering in the conversation. These set-ups were at times more successful than others, and sometimes they resulted in very spontaneous speech.

Parts of the corpus can thus be said to consist of observed communicative events, with most being staged (Himmelmann 1998). Such staged communicative events in the corpus also include narratives and procedural texts, whereby speakers hold a monologue on how to build a house, how to cook a certain dish and so on. A few monologues are based on general instructions, such as "tell me what you plan to do next weekend". The advantage with staged communicative events is that they can be relatively easily recorded and, consequently, transcribed (Mosel 2006).

A few texts in the corpus are based on picture stimuli, for example, from a questionnaire developed to study information structure (Skopeteas et al. 2006). Such texts have been criticized as not forming part of the culture of the community (see Mosel 2006) and thus triggering a different kind of language than narratives from the community. However, they can be helpful when comparing communicative strategies chosen by speakers (Himmelmann 1998). There are no texts based on translations in the corpus, due to obvious reasons of interference (Mosel 2011). Observed communicative events include a wedding speech and songs. While it is likely that certain language practices, registers and genres are missing from this corpus (Mosel 2006; 2012), the intention is to keep adding more material in the future.

Although some of the recorded discussions are about the ancestral code or "pure" form of the specific variety (Woodbury 2005; Marten \& Petzell 2016) - in the South African context, this is referred to, for example, as "deep Xhosa" (Slabbert \& Finlayson 1998) - all recordings are of actual language use. There are no attempts to describe or reconstruct the ancestral code through interviews, and the speech represents contemporary communicative practices. It is always possible that speakers adapt their speech, consciously or not, during a recording. In the case of this project, such adaptation could go both ways, towards the standard or towards the ancestral code, in order to emphasize the linguistic identity (see Section 4.3 for discussion).

To make the corpus available, preparation and editing of the material are necessary. The texts are transcribed in the Xhosa orthography, without prosodic annotation, according to a discourse analysis approach which includes codes for pause, hesitation, overlap and so on, as outlined in Allwood et al. (2005). The use of words from other languages has not been specifically marked as such, in order to avoid having to analyse words as either borrowings or examples of code-switching (Schultze-Berndt 2006). Speakers of Xhosa, mainly students, were trained to transcribe in this way during the project. As noted above, this is a time-consuming process, and the aim in this project has been to strike a balance between detail - with regards to features such as hesitations and overlap - and time (Schultze-Berndt 2006). The texts have been segmented into turns, in the case of dialogues, and roughly into intonation units in other cases (Himmelmann 2006). The texts have been glossed manually according to the Leipzig glossing rules (Comrie et al. 2008, updated 2015).

Several texts also have an English translation, as an aid to understanding the structure of the language. An attempt has been made to keep these translations as close to the source as possible while still retaining readability in English.

The editing of the texts of the corpus is seen as an ongoing process of improvement and fine-tuning, and the results of this project will make it possible to add further annotation at a later stage, such as multi-tier transcriptions including non-linguistic aspects of interaction (Schultze-Berndt 2006). 


\subsubsection{Data gathering in the Eastern Cape}

Recordings were made in different villages throughout the Eastern Cape (see the map on page 107). The selection of these villages was based on a number of factors. First, the aim was to have a geographical spread by visiting different areas. Secondly, certain places were visited because they are supposed to belong to core areas of ethnic groups such as the Hlubi, the Bomvana and so on. However, I did not restrict myself to these, in order to keep an open mind regarding the different aspects involved in variation and to not be led too much by what was to be expected, based on previous literature. Thirdly, it is advantageous to visit places where one has a contact person, that is, someone from the community who can introduce the linguist and their work to the community. This was never a problem; living in the Eastern Cape and working at a local university during the time of research gave me the opportunity to develop a wide network of inhabitants of the province and speakers of the language. The "field" was never far away and I could quickly respond to tips and invitations, such as an invitation to visit the Bhaca people, including King Madzikane II.

Participating speakers were those that volunteered or were recommended through my contacts. In total, approximately 40 speakers contributed to the recordings, sometimes in small groups. Speakers were informed about the session and its aim, in order to give consent, and metadata such as age, the place where they grew up and other languages spoken were carefully registered. Questions also focused on periods living away from the region, the time and place of schooling, and so on, in order to create a basic life story of the speaker (Dimmendaal 2001) and to understand his or her linguistic background and current linguistic practices.

The recordings were made with a Zoom H4n digital recorder. In addition, most recordings were complemented by video recording with a Nikon D5300. The aim of this was to include non-verbal means of communication in the corpus, such as gestures, body movements, locations and contexts (Nathan 2011). Video recordings also assist the transcriber in identifying the speakers. Moreover, using more than one means of recording functions as an additional measure of security against data loss. During recording sessions, a lot of energy and attention is needed to oversee the event and make sure everyone is at ease, while at the same time trying as an outsider - to not influence the recording by one's presence. In the middle of all this, it is possible for recordings to fail due to technical issues; thus, redundancy is an important strategy to overcome such occurrences. Each recording also contains such metadata as the place and time of the recording, the people present and other relevant factors, including technical details. The information about the recording event enables evaluation of the data in terms of its spontaneity and possible influence of the observer's paradox (Himmelmann 1998).

\section{EVALUATING THE VARIATION}

In Section 2, it was shown that no clear indications of geographical morphosyntactic variation can be found in the corpus data. However, as indicated in the introduction, previous literature reports large dialectal differences. It is presumed here that geographical variation played a larger role in the past. Reviewing the literature and comparing the supposed variation therein to the variation found in the current project, we see that certain phonological traits are still present but not easily linked to a certain region. Modern-day variation in the Eastern Cape is examined in relation to other factors. Apart from generational differences there is a rural/urban distinction, however slight. Thus, it can be argued that previous regional variation has declined 
over the years. To this end, I present sociolinguistic factors that are proposed to have played a role in this decline.

\subsection{The languages of the ancestors}

Publications giving information on variation in Xhosa are scarce and relatively outdated. This introduction gives an overview of the available material. Afterwards, certain dialects will be discussed separately.

Almost all publications are theses, mostly at the level of master's or honour degrees, and hard to come by. The first source to mention variation is Soga (1930). Even more scarce are publications based on first-hand data. Cantrell (1974) - and the master's thesis by the same author cited therein (Cantrell 1946) - reports on Mpondo, with details on phonology, the copula and forms of greetings, among others. The most complete report on any variety of the cluster that I have seen is a master's thesis on Bhaca (Jordan 1942). This study was conducted in the tradition of dialectal fieldwork, including interviews with authorities on the "pure" variety in question. First-hand data is presumably also used in Pahl (1983), a grammar of Xhosa (written in Xhosa) with a separate chapter on regional variation, including examples. The data appears to have been contributed by speakers of the different varieties, but further metadata is not given.

In some cases, publications reiterate earlier results, such as the overview by Nyamende (1994), which mainly follows Pahl (1983). There are also a few studies that have a more sociolinguistic focus, such as Thipa (1989), whose main conclusion is that rural varieties use codeswitching, slang and borrowing less than urban varieties. Gxilishe (1996) has an educational focus but does not provide linguistic detail. Nomlomo (1993) also has an educational focus but gives details on phonology and lexicon from interviews with elder speakers of the varieties. In all of these sources, the information given is mainly phonological and lexical, only rarely regarding morphosyntax. Jordan (1942), for example, reports that syntactical differences are practically negligible. Also, Nomlomo (1993) points out that differences between varieties may be found in phonetics, phonology, intonation and lexicon. Certain general grammars offer additional details on variation here and there in terms of specific constructions (e.g. Louw \& Jubase 1963; Oosthuysen 2016). Further sources are given below for the relevant variety.

In the present work, only a few of the dialects are discussed in detail. These are the dialects of Mpondo, Bhaca and Hlubi, which could be expected to be more distinct from the standard, based on the views of speakers of these varieties as well as those of standard Xhosa speakers. Data has been collected in the areas where these varieties are spoken. Due to time constraints, Xesibe ${ }^{26}$ has not been included. Mpondomise, another variety considered to be very closely related to Mpondo,

\footnotetext{
26 The Xesibe variety is supposed to be very close to Mpondo (Cantrell 1975b). Pahl (1983: 262) calls Xesibe "the sibling that follows the twins Mpondo and Mpondomise". According to Doke (1954: 91), however, Xesibe tends towards the Tekeza cluster. The Xesibe people occupy land in the Mount Ayliff District in Transkei (Nyamende 1994). Pahl (1983) reports that women, or even just old women, are the only ones to still use Xesibe to some extent. Xesibe is reported to use [t $\mathrm{t}$ ] where the standard has [ $]$ ], just like Mpondo and Mpondomise, according to Nomlomo (1993), who cites Jordan (1956). The Xesibe are also said to use ukundrondrosa and say ndrihlala 'I live/stay' rather than ndihlala (Cantrell 1975b: 14). Other noteworthy differences are the shortened forms $u b a$ and noba, where Xhosa has $u k u b a$ 'that' and nokuba 'whether', and demonstratives that resemble Mpondo in that they drop the lateral /1/: eyo ndroda (standard leyo ndoda 'that man'), awa magutsha (lawa magusha 'those sheep', normally a plural in noun class 10). In Xesibe, the copulative with the pronoun in the first-person singular is ndrim or ngumi (standard ndim 'it is me'), with the latter resembling Mpondo (Cantrell 1974: 14).
} 
is briefly considered, along with Thembu and Bomvana; these are all varieties spoken further south than Mpondo, Hlubi and Bhaca, and which are very close to the standard.

The Phuthi language (S404) is not included here. It is spoken mainly in Lesotho, and is a "Sotho-Nguni hybrid" (Donnelly 1999). Although there are presumably pockets of speakers in the northern part of the Eastern Cape, their whereabouts are unclear and remain to be examined (Donnelly 1999). Details of Phuthi as spoken in Lesotho are relatively well known, as the language is the topic of an extensive dissertation with a focus on tonology but also grammar (Donnelly 2007). Also, there is an ongoing documentation project. ${ }^{27}$ Although under threat, Phuthi appears to still be used, with children as yet acquiring the language, at least in Lesotho (Donnelly 2007).

Other glossonyms are found in some sources, such as Mfengu (Nordhoff et al. 2013). Mfengu is referred to as Old Mfengu by Doke (1954: 24), but according to him, it is extinct. Nyamende (1994) corroborates that the Mfengu people of the Butterworth, Ngqamakhwe, Tsomo and Peddie districts have lost most of their original variants, preferring standard Xhosa. The Mfengu people are also referred to as the abaMbo (Pahl et al. 1989) or as the Fingo people. It is possible that this was a pseudo-ethnicity, a term used to refer to people of different origins - including the Gcaleka Xhosa - brought to the Cape Colony in the nineteenth century to assure a labour supply for white settlers (Stapleton 1996). Maho (2009) adds Hlubi (in former Ciskei) as a variety, which is not the same as Hlubi S403. I have not been able to find any other sources on this variety, nor any of its speakers. Apart from these varieties there are further ethnonyms sometimes considered dialects of Zulu and sometimes Xhosa, such as Ntlangwini ${ }^{28}$ and Cele. ${ }^{29}$

The following map (Figure 2) gives an idea of where different groups are considered to have their homes, based on the literature. The ethnic groups that are considered to speak or have spoken regional varieties different from the standard are indicated with capital letters. Moreover, I have indicated in which places data collection has taken place during the project: these villages are indicated with red dots. Other place names are provided for reference.

\footnotetext{
27 Sheena Shah of the University of Hamburg: <sheenashah.co.uk/siphuthi.html>.

28 Spoken in the Mzimkulu area in Kwa-Zulu Natal as well as in the Matatiele district in the Eastern Cape, Ntlangwini is described as a "Tekela-Nguni" variant (Louw \& Jubase 1963: ix; Nyamende 1994). A doctoral thesis not available to me (Msimang 1989) gives an overview of the history and geographical distribution of Bhaca, Ntlangwini and other Nguni varieties, concentrating on phonological differences, according to Donnelly (1999). Ntlangwini is reported to be influenced by standard Zulu and Xhosa (Zungu 1989), as cited in Nyamende (1994). Ntlangwini shares the ukutekeza way of speaking with Bhaca; see below. An example is ititiba 'pools', where standard Xhosa has iziziba. The Xhosa locative morpheme se- is ke- in Ntlangwini (Zungu 1989), as cited in Nyamende (1994); e.g. nakekhaya 'also at home' and not nasekhaya, as in standard Xhosa. The data published by Msimang is also cited in Nomlomo (1993).

29 Where the Tekeza varieties use /t/ and the Zunda ones use / $\mathrm{z} /$, Cele uses the affricate /tz/, such as seen in intombatzana instead of intombazana 'girl' (Pahl 1983). This is claimed to be a feature of the Lala group (Nyamende 1994). Lala is included in the Tekeza group (Gowlett 2003), and it is spoken in the KwaZulu Natal province (Zungu 1999). Part of the Cele people migrated south into the Mpondo area, where they were given land in Lusikisiki (Nomlomo 1993). They are supposedly still there but their variety is heavily influenced by Mpondo and Xhosa (Pahl 1983; Zungu 1999).
} 


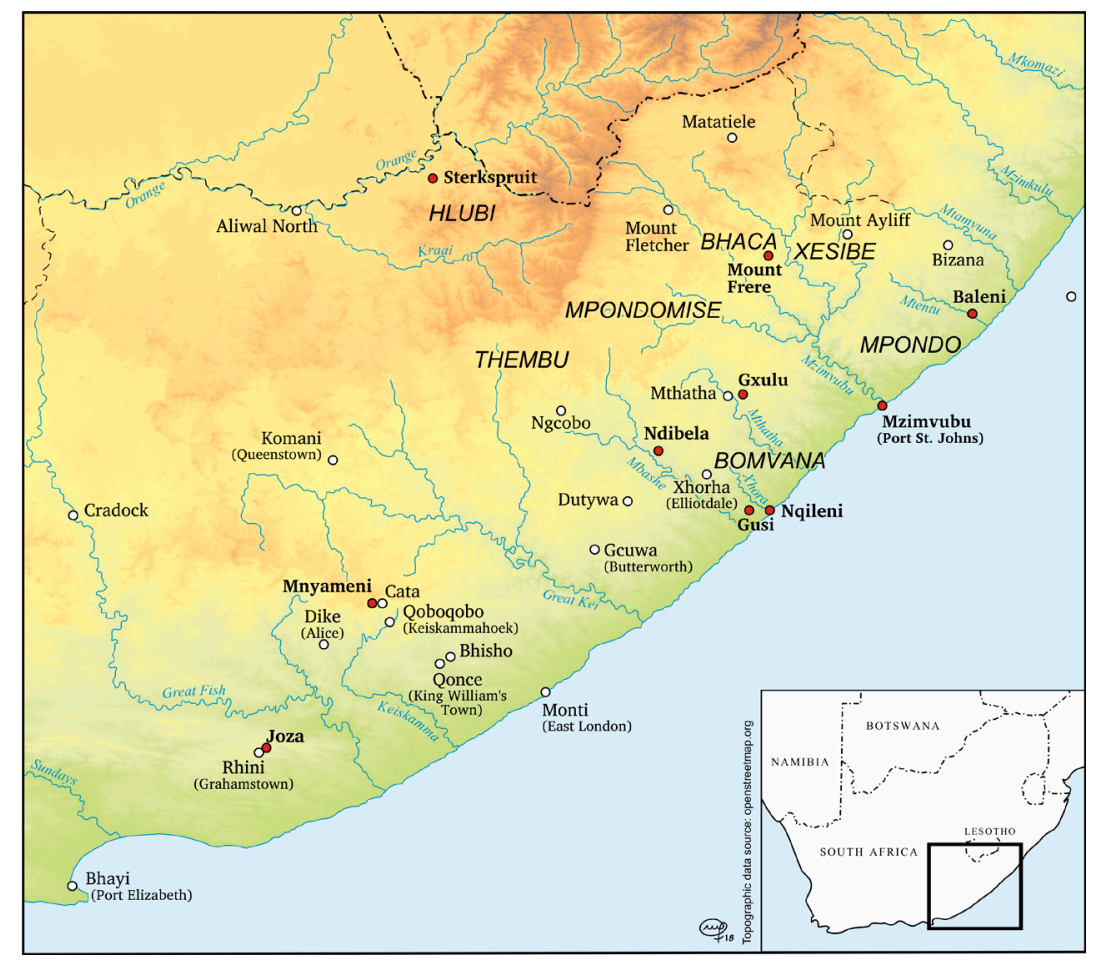

Figure 2 Map of Eastern Cape (by Monika Feinen)

\subsubsection{Thembu, Bomvana and Mpondomise}

The Thembu live in the districts of Ngcobo, Mthatha, Mqanduli and Elliotdale (Nomlomo 1993; Phoofolo 2005). The Bomvana people also live in the districts of Elliotdale and Mqanduli, and at the coast, between the rivers Mbashe and Mthatha (Nomlomo 1993; Kirsch \& Skorge 2010: XII). Mpondomise speakers can reportedly be found in St. Cuthbert (Tyabashe 2006) and in the districts of Qumbu and Tsolo (Nomlomo 1993).

All of these three glossonyms are supposed to refer to varieties that do not differ much from the standard (Louw \& Jubase 1963: ix; Pahl 1983: 257). There are a few differences from standard Xhosa that Thembu has in common with Bomvana and Mpondomise, according to Pahl (1983). Apart from aspirating in many cases where the standard has $k$, certain verbs start with the vowel $o$ in these all of these varieties (and not in the standard); for example, $u k \dot{u}$-mbà 'dig' is $u k$-ómbà. ${ }^{30}$ The demonstrative copulative forms are used with $k$; one finds nankuya instead of nanguya 'there it (ncl.3) is', according to Nomlomo (1993), who cites Mbadi (1956), an honours thesis which is not available to me. The decline of the use of these varieties is also reported on. For example, as reported in Nyamende (1994), Mbadi (1956) had to interview elderly people without a formal education to get data for his thesis.

I did not find the specific variables described above during data collection. Recordings were made in Gxulu outside Mthatha, in Ndibela close by Qunu, in Gusi in Elliotdale, and on the coast in Nqileni/Bulungula. Only in Nqileni, among the Bomvana, did I find some non-

30 Tone marking is from The Greater Dictionary of IsiXhosa (Pahl et al. 1989-2006). In the dictionary, the form ukómbà is marked as Mbo. 
standard forms. The older man in Example (1) above used several phonological variants typical of Mpondo (see below). This should not surprise us, considering the closeness of the varieties and the sociolinguistic situation described in Section 4.4.

\subsubsection{Mpondo}

Mpondo people live along the coast, to the north of the Mthatha River all the way up to southern Kwa-Zulu Natal (Cantrell 1975a). The main districts in which Mpondo is spoken are Lusikisiki, Libode, Flagstaff, Port St. John's, Bizana and Tabankulu (Nyamende 1994). Data collection among people referring to themselves as Mpondo was carried out in Port St. Johns. Further to the north and in much more rural locations, we made recordings in Baleni in the Bizana district.

Due to influence by standard Xhosa, it was reported as early as 1974 that "certain language forms are to be heard among the Mpondo people today" but that "it is no longer possible to say dogmatically that this or that form is true Mpondo" (Cantrell 1974: 10). Cantrell (1975b: 13) added that the varieties with lesser influence from Xhosa are spoken in the forest areas and along the coastal areas between the Umtamvuna and Umzimvubu rivers, as well as kwaMzizi in Bizana.

According to the available literature, there are a number of phonetic and phonological differences between Mpondo and standard Xhosa, such as the use of an ejective velar affricate [ $\left.\mathrm{kx}^{2}\right]$ where Xhosa has $\left[\mathrm{k}^{?}\right]$ : for example, [iints $\mathrm{ukx}^{\mathrm{l}} \mathrm{u}$ ] 'days' relates to Xhosa [iints' $\mathrm{k}^{\mathrm{l}} \mathrm{u}$ ] (Cantrell 1974). Most importantly, Mpondo is claimed to be characterized by a phonological phenomenon referred to as ukundrondrosa 'to ndrondroza'. This involves a rhotic where standard Xhosa does not have one, as in intrombi 'girl' instead of intombi, and inkrwenkrwe instead of inkwenkwe (Nyamende 1994). Neither the ejective velar affricate nor the ukundrondroza phenomenon are heard at all in the corpus and elicited material.

The reported forms of the Mpondo demonstratives without $l$ - in the medial and distal are not encountered in the material. According to Pahl (1983), the Mpondo say eya ndlu 'that house', where Xhosa has leyo/loo ndlu. I have not found this in the corpus data; rather, examples of the standard forms can be found:

$$
\begin{aligned}
& \text { 16. nga-lo mini leyo } \\
& \text { INS-9DEM.MED } \\
& \text { 'on that day' }[\text { BLN150925D_c }]^{31}
\end{aligned}
$$

The auxiliary -ve that is reportedly used in Bhaca negation appears to have a counterpart in Mpondo in the negation of the copula, according to Cantrell (1974). Here, avi is supposedly followed by the copulative, as in avi ngum owo 'it is not I'. Variants on this are found, such as ayivi in ayivi lilo elo 'that is not it' (referring to ihatshi 'horse' in class 5), according to Cantrell (1974: 14). The auxiliary also occurs as -ve in certain constructions in Western Mpondo: eli hashe ayive elelakho 'this is not your horse' (Cantrell 1974: 16). This negative -ve is not attested in the data.

31 Sikhuthele Chris Ncamani, male, 30 years. 


\subsubsection{Bhaca 5402}

Bhaca is claimed to have undergone change due to heavy influence from Xhosa and other language varieties spoken in neighbouring districts (Jordan 1942; Louw \& Jubase 1963; Pahl 1983: 266). Jordan even claims that Bhaca is "being stifled to death" (Jordan 1942). However, Pahl (1983) notes that especially elders are quite attached to their language. Bhaca people occupy land in the districts of Mount Frere and Mount Ayliff in the Eastern Cape and Umzimkulu in KwaZulu-Natal (Jordan 1942; Nyamende 1994). According to Louw and Jubase (1963: ix), Bhaca is a Tekeza dialect which is closely related to Swati and Ntlwangwini.

As in other varieties considered to belong to the Tekeza group (see Section 1.1), Bhaca has /t/ where Xhosa has /z/, so that ukuzibona is heard as ukutibona 'to see oneself' (Jordan 1942). This phonological difference still exists, as evidenced by the form abafati 'women' (standard abafazi) [MTF170609D_c]. This is also the case with ukutshefula (Jordan 1942). This means that a sibilant follows the / $\mathrm{t} /$. We see this in -tshandza (standard -thanda) 'like' in the following example. The same verb also shows the use of $/ \mathrm{dz} /$ instead of $/ \mathrm{d} /$, representing one of the differences from the standard, according to Jordan (1942: 2):

17. $i$-nt $(o)$ e-ndi-y(i)-thsandza-yo

9-thing 9RC-SM1SG-OM9-like-REL

'the thing I like...' [MTF170609D_c] $]^{32}$

However, Example (17) also shows that into 'thing' is pronounced just like in the standard. I find no trace of the three consonant clusters that have been claimed to exist in Bhaca but not in Zulu or Xhosa: /tf/ as in intfo 'thing' (Xhosa into), /dv/ as in idvolo 'knee' (Xhosa idolo), and /thf/ as in -thfuma 'send' (Xhosa -thuma) (Jordan 1942). A phonological difference that does persist until the present day is $/ \mathrm{kh} /$ instead of standard $/ \mathrm{h} /$, as in the following example, for which the standard would have abasahambi:

18. $a-b a-s a-k h a m b-i$

NEG-SM2-anymore-go-NEG

'They do not go anymore' [MTF170609D_1] $]^{33}$

The 1st-person subject marker is heard as $n d i$ - (also in standard Xhosa) as well as ngi- (in Zulu); in fact, the same speaker can use both in a conversation.

One of the more interesting reported morphosyntactic differences between standard Xhosa and Bhaca is that the latter distinguishes between a conjoint and a disjoint ${ }^{34}$ form in certain negative forms (i.e. the present, the perfect and the future). Xhosa only has this distinction in the affirmative. For other Bantu languages also, a disjoint/conjoint distinction in the negative is rare, and it appears mostly to be indicated tonally (van der Wal 2017). ${ }^{35}$ The distinction is morphological in Bhaca and formed as follows. The disjoint or long form andikhambi 'I am not going' in Bhaca corresponds to the negative found in Xhosa andihambi (Jordan 1942). The

\footnotetext{
32 Princess Nomanyano, female, 30 years.

33 Young girl.

34 This terminology refers to certain tense/aspect/moods having two morphologically distinct forms: the conjoint, which is used when the verb is in a close bond (syntactically, phonologically) with what follows and the verb has to be followed by an object or an adverb, for example, and the disjoint form, which is used when there is not such a close bond and which can also occur independently (see van der Wal \& Hyman 2017).

35 As reported for Makhuwa and Southern Sotho.
} 
second form (conjoint) is reported by Jordan (1942) to exist in Mpondo as well and almost exclusively used when the verb is followed by an object or adjunct. This form makes use of a verb -ve (not used elsewhere) inflected with a negative formative $a$ - and optional subject marker. The following is an example of the present tense conjoint:

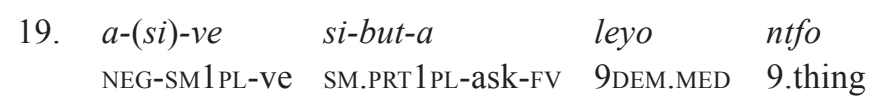

'We are not asking that.' (Jordan 1942: 40)

As standard Xhosa does not make a distinction between the conjoint and disjoint in the negative, this would be asibuzi leyo nto.

In the perfect, the conjoint form of the negative is also formed with -ve, followed by the participial recent past perfective form (Jordan 1942):

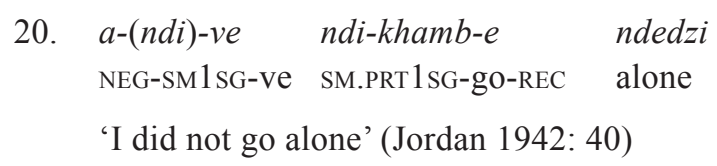

Standard Xhosa would have been a-ndi-hamb-anga ndodwa [NEG-SM1SG-go-NEG alone]. Even more interesting is that the future negative also makes this distinction, while there is no distinction in the future affirmative. Therefore, ndita khamba 'I am about to go' is negated as andit(i) uukhamba 'I am not about to go' when the verb has no adjunct (Jordan 1942: 41). When something follows, however, a conjoint form is used, as seen in Example (21b). This can be compared with the positive in Example (21a):

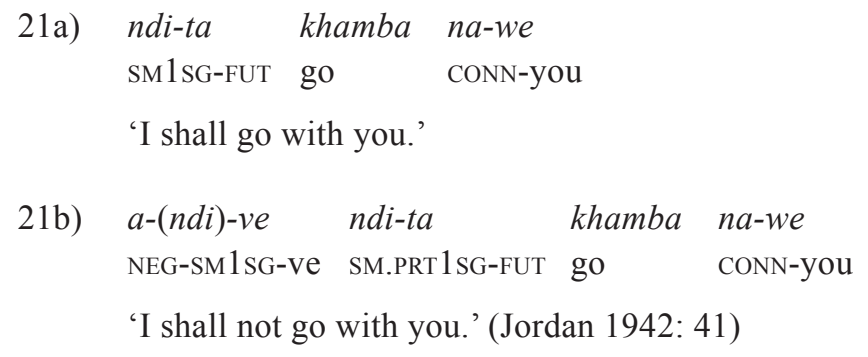

Jordan (1942) also reports on a similar distinction in the remote future.

In the corpus data we find just one example of the -ve form, in what appears to be a disjoint present form. The whole utterance was hard to hear for the transcriber and is therefore bracketed:

22. (a-ve u-(ya)-ba-thsanz-(a) (kaloku) oo-thonqo)

NEG-ve SM1-DJ-OM2-love-FV you.see 2a-foolish.person

'She doesn't like foolish people.' [MTF170609D_c] $]^{36}$

The distinction is not productive. Other negative forms in contexts that require a conjoint form appear in the form expected in standard Xhosa:

36 Makheswa Bekezulu, female, 78 years. 

23. $a-n-a t-i$
$s($ i) - Bhaca
NEG-SM2PL-know-NEG 7-Bhaca
'You (pl) don't know Bhaca (lg).' [MTF170609D_c] $]^{37}$

\subsubsection{Hlubi S403}

Considered a dialect at the Xhosa/Zulu point of contact (Donnelly 1999: 117), Hlubi is spoken in South Africa as well as Lesotho. The Hlubi communities are found in the north-eastern part of Eastern Cape, presently referred to as the Joe Gqabi District. A considerable number of Hlubi speakers were also reported by Jordan (1942) to reside in Mount Frere. Following an invitation from a Hlubi interest group, interviews were held for this project in Sterkspruit and Herschel. Of the main characteristics reported for Hlubi (Pahl 1983), we did note the use of $n g$ ' instead of $n d$ in some instances, such as angazi 'I do not know' (standard andazi) [STP160501D_a], although $n d i$ - is also frequently heard for the 1st-person singular concord. Vowel initial verbs frequently start with the vowel $e$ rather than $a$, as in ndiselusa 'I was herding (sheep)' (standard ndisalusa) [STP160501D_a]. ${ }^{38} \mathrm{~A}$ few cases of morphosyntactic differences are given in Section 2; see Examples (12) and (13). Otherwise, information on this variety is scarce, as is also pointed out in Nomlomo (1993). Tone and intonation are reported to be "more like Zulu than Xhosa" (Nomlomo 1993).

To summarize here, we can say that several phonological variables occur in varieties spoken in the Eastern Cape, although in several instances variants alternate with the variants used in the standard language, even for the same speaker. Of the different varieties, it is safe to say that Bhaca shows the most alternate forms.

\subsection{Factors of variation}

As pointed out by, for example, Chambers and Trudgill (1998), there are many aspects of societal differentiation - such as social class and sex - that can be connected to linguistic variation. Based on the limited set of data analysed for this study, the following patterns of variation can be noted. Older speakers use more non-standard forms. Young persons with a rural background tend to use verbal forms that are less reduced (i.e. they still consist of an auxiliary and a main verb). This is not heard with young urban speakers.

The phonological and lexical differences noted above (and also in Section 4.1) are still present to some extent. In recordings with the Bhaca people around Mount Frere, the differences are part of the speech of all recorded participants. In other parts of the Eastern Cape, notably among the Mpondo in the north and the Bomvana on the coast, the phonological variables are heard amongst elder speakers but not the young speakers recorded. In some instances, however, these younger speakers do use lexemes that seem specific to the region.

Therefore, it can be concluded that the traditional dialects of the Eastern Cape are used to a limited extent in present-day South Africa and that they are being affected by language change. The variation encountered in the project provides evidence of traces of the traditional dialects. This does not mean that there is no variation between the standard and the language spoken in the home, but it suggests other factors than regional variation. There is also considerable varia-

37 Princess Mamaduna Sigudu, female, 75 years.

38 Also in Mpondomise, Thembu and Mfengu, according to Pahl et al. (1989-2006). 
tion in urban areas due to different kinds of "tsotsitaal" and youth language, but this is not dealt with in this work (see, e.g., Hurst 2015).

\subsection{Dwindling language use}

The project "Morphosyntactic variation in the dialects of Xhosa" aimed to illuminate any existing linguistic variation in the Eastern Cape. The reference to dialects of Xhosa in the title makes the project's scope of language and geography quite clear for an outside community (for example, researchers). However, this is not acceptable to people belonging to certain ethnic communities, such as the Bhaca. Strongly held opinions of differences between linguistic varieties are striking across the whole northern part of the Eastern Cape. People of the Mpondo ethnicity argue that the isiMpondo language differs considerably from Xhosa, people of the Hlubi ethnicity argue the same for isiHlubi, and so on, maintaining that they are not able to speak Xhosa.

Speakers give considerable weight to phonological differences when reporting their different varieties, presumably because phonological differences are more easily identified than differences in morphosyntax. In fact, groups are identified based on certain properties of their speech, with verbs indicating a specific pronunciation. Examples are ukutekeza, ukundrondroza and ukutshefula. This is not unexpected, as speakers recognize regional syntactic variation to a lesser extent than phonological variation (Bucheli \& Glaser 2002). Such opinions on differences are quite old, as illustrated by a quote from Soga: "On account of the striking character of Si-Xosa it is impossible to class the Ama-Xosa with the tekeza group of tribes" (Soga 1930: 87). There is, however, almost complete mutual intelligibility in the region.

The emergence of distinct ethnolinguistic identities in the area is likely to stem from the fact that the Xhosa people recognize clans and lineages whose names often refer to chiefs and ancestors. The names of the groups introduced in Section 1.1 refer to such forefathers. For example, Ngqika was Rharhabe's grandson, and Ndlambe was the uncle of Ngqika (Peires 1982). References to different groups of people by these ethnonyms differ from author to author, and it also varies which people are included in a certain ethnonym. According to Peires (1982: ix), "Xhosa" actually refers to people who accepted the rule of the chief Tshawe, who are referred to as the Rharhabe and Gcaleka. Peires (1982) mentions Thembu, Mpondo, Mpondomise, Bhele, Zizi, Hlubi and Bhaca as other Xhosa-speaking peoples, with histories of their own. Moreover, he shows how the heterogeneous Xhosa nation has expanded through the incorporation of people of different origin - like, for example, many groups of Khoi people - and it is not "a genetically defined 'tribe' clearly distinct from its neighbours" (Peires 1982: 19).

As the results from this study show, the variables that are reported to exist in the literature are not - or only in a very limited way - used at present in daily communication. If we assume that the mentioned dialects were distinct varieties at some point, their use is now waning to such an extent that they can be considered heavily endangered.

Even though the members of these groups hold their culture in high esteem, speaking a regional variety is not connected with prestige when leaving the home area, and therefore it is not connected with social mobility and economic success. What we see here can be considered as a clash between use of the Xhosa standard, which is more prestigious than other varieties (Nyamende 1994), and the signalling of one's identity as a member of a group through the use of a regional variety, much like the covert prestige of low-status linguistic forms discussed by Chambers and Trudgill (1998: 85-86). However, in this case, the covert prestige does not 
necessarily result in actual language behaviour. A gradual language shift possibly took place (Mithun 2001), perhaps without the speakers being overtly aware or even worried about it. Speakers of endangered varieties can have a strong sense of identification with their language even without teaching it to their children (Austin \& Sallabank 2011). In the case of Mpondo and other Xhosa varieties, the identification appears more connected to tradition and culture than to language. To admire one's culture and to have a positive attitude to the ancestral language do not necessarily imply learning the language, as pointed out by Dimmendaal (2015).

Some members of certain of these communities are acutely aware of the decline of language use, of course. Our visit to the Hlubi community was initated by an invitation by a group concerned not only with the documentation of isiHlubi but having the ultimate aim of promoting their variety to the status of an official language, along with Xhosa and Zulu. Recognition of a distinct language, including writing and teaching it, enhances the self-esteem of a group (Dimmendaal 2015). The Bhaca community is also strongly interested in preserving their variety, as explained to me in personal communication with King Madzikane II.

Another scenario should be considered. It has been pointed out in the literature of language endangerment in Africa that the language ecology in different communities can be highly complex and that speakers shift between different repertoires in their multilingual realities (Lüpke 2015). Monolingualism is rarely the norm. That limited variation is found in the recordings of speech events might also be the result of unconscious use of a certain repertoire in a recording setting, regardless of all our precautionary measures. It is also quite possible that variation in the concerned speech communities was never substantial, as the differences reported on in previous publications are in fact not very large. What can be safely concluded is that any loss of linguistic diversity has not affected the sense of identity of belonging to one of the clans or groups. Their locality and descent are important to them, without these necessarily (any longer) being connected to a language (see the Tima speech community; Dimmendaal 2015).

Having concluded that regional variation in the Eastern Cape has most likely declined over several decades, if not more, we now turn to the aspects of life in this area that may be proposed to have led to the current situation.

\subsection{Social aspects of variation}

Several sociolinguistic aspects of the Eastern Cape which came to light during the course of the project are important for understanding the place that language holds at present in the different communities. ${ }^{39}$

Large-scale European dialect projects have often concentrated on a so-called NORM (Non-mobile, Older, Rural Male) speaker, as this group is supposed to retain their native language more than others (Chambers \& Trudgill 1998). However, in the Eastern Cape it has been - and is still today - very common for men to work in the mines in northern South Africa. In fact, men in their thirties and forties are not often seen in some villages. For example, older men report living in Rustenburg for two decades, only coming home two or three times a year.

Apart from learning other languages when working away from home for such a long time, these men are also exposed to urban registers such as "urban Xhosa" and different kinds of "tsotsitaal" (Hurst 2015). Such urban multilingualism is likely to have affected the language

39 I am thankful to Mark de Vos for discussion and bringing some of these aspects to my attention. 
of the migrant worker as well as others in their place of origin. Therefore, in the Eastern Cape one does not find the expected non-mobile person who retains the speech of older generations.

Another aspect that could possibly influence language is that in the Xhosa tradition, marriage between members of the same family or clan is prohibited. The interpretation of the term "bloodrelationship" is much wider than in other societies (Soga 1930: 79). Upon marrying, women move to the household of their husband, sometimes a great distance away. Women adapt to the linguistic variety spoken in the new household but also most likely retain some part of their register and contribute to the multilingual complexity of the area. For comparison, in the analysis of Swiss German dialects by Bucheli and Glaser (2002: 53), answers from consultants who had moved away from the place they grew up or whose parents were not from the place of investigation were removed. Such an approach appears not only undesirable but immensely difficult, if not impossible, in the Eastern Cape.

Furthermore, in Xhosa culture, a married woman avoids the use of the names of her husband and in-laws, specifically the father-in-law and other elder males of the new family (Finlayson 1982). ${ }^{40}$ In fact, married women also need to avoid words that resemble these names or even syllables and sounds occurring in them. Instead, they use alternate terms or make up other words. This avoidance language is called ukuhlonipha. The use of ukuhlonipha is dwindling (Kaschula \& Anthonissen 1995: 22), but it is still observed in rural areas of the Eastern Cape. The custom has led to the development of a considerable number of alternative forms, many of which are listed as such in The Greater Dictionary of IsiXhosa (Pahl et al. 1989-2006). ${ }^{41}$ As married women live in the homestead of their husbands, many women can share the same in-laws, and the use of certain hlonipha words can become widespread.

Ukuhlonipha affects a woman's language use in a way that would mislead any dialectologist looking for isoglosses. In fact, this extends to a general taboo of larger groups. According to Kaschula and Anthonissen (1995: 25), the Zulu avoid royal names. This has resulted in the adoption of the Xhosa word for 'root', ingcambu, in order to avoid the original term impande, which was too close to the name of King Mpande. In such a situation, one must be very careful when trying to determine the borders of dialects based on lexicon.

Lastly, one should not forget the long history of resettlements, colonialism and Apartheid. The Eastern Cape has seen immense turmoil over the centuries, from colonial wars and the forceful displacement of groups of people to create space for European settlers (Legassick 2010) to the influence of the colonial languages English and Dutch, and later Afrikaans. This was followed by the language policy of Apartheid, with mother-tongue schooling representing low-quality "Bantu education" and becoming associated with racial segregation (Reagan 1987). All in all, "the linguistic and cultural history of southern Africa is an enormously complex web of migrations, conquests, assimilations, and diversifications" (Herbert 1990: 306). Of course, added to this is variation that can be found in any speech community, based on the socio-economic layering of the society, on age and gender, and on registers related to politeness and avoidance.

\footnotetext{
40 There is more complexity to this, and there is also variation. For example, the name of the mother-in-law is sometimes avoided. The married man can also avoid the names of his in-laws.

41 In fact, the introduction of clicks into Xhosa, as a borrowing from Khoisan languages, has been attributed to the custom of ukuhlonipha (Herbert 1990). Intermarriage between Xhosa men and Khoisan women was common, and these women were introduced to Xhosa customs. When they needed to adopt alternate forms of words in order to avoid the names of their in-laws, they simply introduced Khoisan words. Also, click sounds were introduced in Xhosa words. One example is the Proto-Bantu root *lima 'extinguish' (-zima in Swahili), which is -cima in Xhosa, with the dental click (Herbert 1990).
} 


\section{CONCLUSIONS}

Linguistic varieties do not exist in a geographical vacuum where dialect borders and isoglosses can easily be drawn on a map. This is especially the case in the South African context. Speakers of the Southern Bantu languages are more often than not multilingual and use traditional regional varieties alongside more dominant varieties, including English and Afrikaans. There also exist more recently developed varieties for intra-ethnic communication. In this web of linguistic varieties and repertoires, the current project aimed to answer the question of how such variation manifests itself at present, taking the sociolinguistic situation of the area into careful consideration. Due to the specific setting of the Eastern Cape, the choice was made early on in the project to not attempt to describe homogenous codes or the conservative forms of language that these speakers represent. Instead, variation was approached from a more open perspective. The way in which people speak in actual everyday life is interesting, regardless of sex, age or mobility, to name but a few factors.

From the results of this project it can be concluded that there is very little morphosyntactic variation in the Xhosa dialect cluster, with some allomorphs in the copulative and in the recent past imperfective, along with variation in whether complex verb forms are contracted or not. There is still phonological variation as well as differences in the lexemes used. Of the geographical areas investigated here, it can be said that such variation is stronger around Mount Frere, the area of the Bhaca people and kingdom. Apart from this specific location, the variation encountered could not be linked to a particular region but rather appears connected to generational and rural/urban differences. However, analysis of a larger amount of data would be needed in order to draw such a conclusion with significant confidence.

The results are based on recordings of people in conversation or engaging in different kinds of monologues. There was no morphosyntactic variation that could be pinpointed during initial elicitation, and all examples of variant forms are based on analysis of transcribed and glossed recordings. It has been argued in this paper that such an approach is necessary when variation is on a very fine, intralinguistic level and little is known about possible differences in linguistic constructions. When variation is found, it is possible for future research to conduct a more directed elicitation of specific forms in order to determine the extent of such variation, and also how it is linked with sociolinguistic variables such as age and sex.

The project also concludes that regional variation previously reported on in the literature is disappearing. It is argued that the loss of linguistic diversity is the result of a long history of resettlements and mobility, including continuing migrant labour due to which members of the community spend large parts of their lives in urban areas to provide for family members back home. Not waning, however, is a strong sense of identity connected to a clan or kingdom and geographic area. This identity is not paired with variation in speech when compared to standard Xhosa. 


\section{ABBREVIATIONS}

$\begin{array}{ll}\text { APPL } & \begin{array}{l}\text { applicative } \\ \text { AC }\end{array} \\ \text { AS } & \begin{array}{l}\text { adjectival concord } \\ \text { CJ }\end{array} \\ \text { conjoint } \\ \text { COP } & \text { connective } \\ \text { DEM } & \text { demonstrative } \\ \text { DST } & \text { distal } \\ \text { DJ } & \text { disjoint } \\ \text { FUT } & \text { future } \\ \text { FV } & \text { final vowel } \\ \text { INF } & \text { infinitive } \\ \text { INS } & \text { instrumental } \\ \text { IPFV } & \text { imperfective } \\ \text { LOC } & \text { locative } \\ \text { MED } & \text { medial } \\ \text { NEG } & \text { negative } \\ \end{array}$

$\begin{array}{ll}\text { OBL } & \text { obligative mood } \\ \text { OM } & \text { object marker } \\ \text { PASS } & \text { passive } \\ \text { PL } & \text { plural } \\ \text { PRT } & \text { participial } \\ \text { PRO } & \text { pronoun } \\ \text { PRX } & \text { proximal } \\ \text { PST } & \text { past } \\ \text { Q } & \text { question particle } \\ \text { RC } & \text { relative concord } \\ \text { REC } & \text { recent past } \\ \text { REF } & \text { referential demonstrative } \\ \text { REL } & \text { relative } \\ \text { SBJV } & \text { subjunctive } \\ \text { SG } & \text { singular } \\ \text { SM } & \text { subject marker } \\ & \end{array}$

Numbers 1-17 refer to noun class numbers. 1 st and 2 nd person are indicated as e.g. $1 \mathrm{sg}, 2 \mathrm{PL}$.

\section{REFERENCES}

Alexander, Neville 1998. The Political Economy of the Harmonisation of the Nguni and the Sotho Languages. Lexikos 8: 269-275.

Allwood, Jens, Rusandré Hendrikse \& Mfusi Mmemezi (eds) 2005. Guidelines for Developing Spoken Language Corpora. (Spoken African Language Corpora Series) Pretoria, South Africa: UNISA, Dept. of Linguistics.

Andrason, Alexander \& Mawande Dlali 2017. Tense and Aspect of Performatives in IsiXhosa. South African Journal of African Languages 37: 149-161.

Austin, Peter K. \& Julia Sallabank (eds) 2011. The Cambridge Handbook of Endagered Languages. Cambridge: CUP.

Austin, Peter K. \& Julia Sallabank 2011. Introduction. In: P.K. Austin \& J. Sallabank (eds): 1-24.

Barbiers, Sjef, Leonie Cornips \& Susanne van der Kleis (eds) 2002. Syntactic Microvariation. Amsterdam: Meertens Institute. $<$ meertens.knaw.nl/books/synmic $>$.

Barbiers, Sjef \& Leonie Cornips 2002. Introduction to Syntactic Microvariation. In: S. Barbiers, L. Cornips \& S. VAN DER KLEIJ (eds): 2-12.

Bloom Ström, Eva-Marie 2017. What the Giant Tells Us About Agreeing Post-Verbal Subjects in Xhosa. Stellenbosch Papers in Linguistics Plus 52: 73-100.

Bloom Ström, Eva-Marie \& Malin Petzell in press. Micro-Variation Approaches to Bantu Language Varieties. In: L. Marten, N.C. Kula, J. Zeller \& E. Hurst (eds): The Oxford Guide to the Bantu Languages. Oxford: OUP.

Bowern, Claire 2008. Linguistic Fieldwork: A Practical Guide. Hampshire: Palgrave Macmillan.

Bucheli Berger, Claudia, Elvira Glaser \& Guido Seiler 2012. Is a Syntactic Dialectology Possible? Contributions from Swiss German. In: A. Ender, A. LeEmann \& B. WäLChli (eds), Methods in Contemporary Linguistics: 93-119. Berlin: Mouton de Gruyter.

Bucheli, Claudia \& Elvira Glaser 2002. The Syntactic Atlas of Swiss German Dialects: Empirical and Methodological Problems. In: S. BARbiers, L. Cornips \& S. van der KleiJ (eds): 41-74.

Bybee, Joan, Revere Perkins \& William Pagliuca 1994. The Evolution of Grammar: Tense, Aspect and Modality in the Languages of the World. Chicago: UCP.

Cantrell, John V. 1946. Some Aspects of Mpondo and Its Relation to Xhosa and Zulu. MA thesis, University of South Africa. 
CAntrell, John V. 1974. Some Characteristics of Mpondo. Limi 2: 10-32.

Cantrell, John V. 1975a. Outline of Mpondo Migrations. Limi 3: 27-37.

Cantrell, John V. 1975b. The Relationship between Mpondo and Xesibe Dialects. Limi 3: 13-23.

Carstens, Vicki \& Loyiso Mletshe 2015. Radical Defectivity: Implications of Xhosa Expletive Constructions. Linguistic Inquiry 46: 187-242.

Carstens, Vicki \& Loyiso Mletshe 2016. Negative Concord and Nominal Licensing in Xhosa and Zulu. Natural Language and Linguistic Theory 34: 761-804.

Cassimjee, Farida 1998. Isixhosa Tonology: An Optimal Domains Theory Analysis. München: Lincom Europa.

CAssimjee, Farida \& Charles W. Kisseberth 1998. Optimal Domains Theory and Bantu Tonology: A Case Study from Isixhosa and Shingazidja. In: L.M. Hyman \& C.W. Kisseberth (eds), Theoretical Aspects of Bantu Tone: 33-132. Stanford: Center for the Study of Language and Information (CSLI), Stanford University.

Chambers, Jack \& Peter Trudgill 1998. Dialectology. Cambridge: CUP.

Chelliah, Shobhana L. 2001. The Role of Text Collection and Elicitation in Linguistic Fieldwork. In: P. Newman \& M. RATLIFF (eds): 152-165.

Claughton, John S. 1992. The Tonology of Xhosa. Doctoral dissertation, Rhodes University.

Comrie, Bernard, Martin Haspelmath \& Balthasar Bickel 2008, updated 2015. The Leipzig Glossing Rules: Conventions for Interlinear Morpheme-by-Morpheme Glosses. Leipzig: Max Planck Institute for Evolutionary Anthropology.

Cornips, Leonie 2002. Variation between the Infinitival Complementizers om/voor in Spontaneous Speech Data Compared to Elicitation Data. In: S. Barbiers, L. Cornips \& S. VAN DER KLeIJ (eds): 75-96.

DaveY, Anthony S. 1973. The Moods and Tenses of the Verb in Xhosa. MA thesis, University of South Africa.

Dimmendaal, Gerrit J. 2001. Places and People: Field Sites and Informants. In: P. Newman \& M.S. Ratliff (eds): $55-75$.

Dimmendaal, Gerrit J. 2015. Different Cultures, Different Attitudes: But How Different is "the African Situation" really? In: J. Essegbey, B. Henderson \& F. Mc Laughlin (eds): 37-57.

Doke, Clement M. 1954. The Southern Bantu Languages. London: Oxford University Press for the International African Institute (IAI).

Doke, Clement M. \& Benedict W. VILAKaZI 1958. Zulu-English Dictionary. Johannesburg: Witwatersrand University Press.

Dom, Sebastian \& Koen Bostoen 2015. Examining Variation in the Expression of Tense/Aspect to Classify the Kikongo Language Cluster. Africana Linguistica 21: 163-211.

Donnelly, Simon 1999. Southern Tekela Nguni is Alive: Reintroducing the Phuthi Language. International Journal of the Sociology of Language 136: 97-120.

Donnelly, Simon 2007. Aspects of Tone and Voice in Phuthi. doctoral dissertation, University of Illinois at Urbana-Champaign.

Essegbey, James, Brent Henderson \& Fiona Mc Laughlin (eds) 2015. Language Documentation and Endangerment in Africa. Amsterdam: John Benjamins.

Everett, Daniel L. 2001. Monolingual Field Research. In: P. Newman \& M. Ratliff (eds): 166-188.

Finlayson, Rosalie 1982. Hlonipha: The Women's Language of Avoidance among the Xhosa. South African Journal of African Languages 2: 35-60.

Gippert, Jost, Nikolaus P. Himmelmann \& Ulrike Mosel (eds) 2006. Essentials of Language Documentation. Berlin: Mouton de Gruyter.

Gowlett, Derek 2003. Zone S. In: D. Nurse \& G. Philippson (eds): 609-638.

Gowlett, Derek \& Tessa Dowling 2015. Incipient Merger of Cls 11 and 5 in Xhosa? South African Journal of African Languages 35: 67-81.

Guthrie, Malcolm 1967-1971. Comparative Bantu: An Introduction to the Comparative Linguistics and Prehistory of the Bantu Languages. London: Gregg International.

GxiLishe, Sandile 1996. The Dilemma of Dialect in the Classroom: A Case for Xhosa. Per Linguam Journals 12(1): 1-14.

Herbert, Robert K. 1990. The Sociohistory of Clicks in Southern Bantu. Anthropological Linguistics 32: 295-315. 
Herbert, Robert K. \& Richard Bailey 2002. The Bantu Languages: Sociohistorical Perspectives. In: R. Mesthrie (ed.), Language in South Africa: 50-78. Cambridge: CUP.

Himmelmann, Nikolaus P. 1998. Documentary and Descriptive Linguistics. Linguistics 36: 161-195.

Himmelmann, Nikolaus P. 2006. The Challenges of Segmenting Spoken Language. In: J. GipPert, N.P. HimmelmanN \& U. Mosel (eds): 253-274.

Hurst, Ellen 2015. Overview of the Tsotsitaals of South Africa; Their Different Base Languages and Common Core Lexical Items. In: N. NAssenstein \& A. Hollington (eds), Youth Language Practices in Africa and Beyond: 169-184. Boston: De Gruyter Mouton.

DE JAGER, E.J. 1964. Die geskiedenis van die ama-Xhosa en ama-Thembu. Historia 9: 215-227.

Johannessen, Janne B., Joel Priestley, Kristin Hagen, Tor A. Åfarli \& Øystein A. Vangsnes 2009. The Nordic Dialect Corpus: An Advanced Research Tool. In: K. JokInEN \& E. BICK (eds), Proceedings of the 17th Nordic Conference of Computational Linguistics NODALIDA: 73-80. Northern European Association for Language Technology (NEALT).

Jokweni, Mbulelo W. 1995. Aspects of IsiXhosa Phrasal Phonology. Doctoral disseration, University of Illinois.

JoRDAN, Archibald C. 1942. Some Features of the Phonetic and Grammatical Structure of Baca. MA thesis, University of South Africa.

JoRDAn, Archibald C. 1956. A Phonological and Literary Study of Literary Xhosa. Doctoral disseration, University of Cape Town.

Kaschula, Russell H. \& Christine Anthonissen 1995. Communicating Across Cultures in South Africa: Toward a Critical Language Awareness. Johannesburg: Hodder \& Stoughton/Wits.

De Kind, Jasper, Sebastian Dom, Gilles-Maurice de Schryver \& Koen Bostoen 2015. Event-Centrality and the Pragmatics-Semantics Interface in Kikongo: From Predication Focus to Progressive Aspect and Vice Versa. Folia Linguistica Historica 36: 113-163.

Kirsch, Beverley \& Silvia Skorge 2010. Complete Xhosa. London: McGraw-Hill.

Kortmann, Bernd 2002. New Prospects for the Study of Dialect Syntax: Impetus from Syntactic Theory and Language Typology. In: S. Barbiers, L. Cornips \& S. van der Kleit (eds): 185-213.

Kortmann, Bernd 2004. Introduction. In: B. Kortmann (ed.), Dialectology Meets Typology: Dialect Grammar from a Cross-Linguistic Perspective: 1-10. Berlin: Mouton de Gruyter.

Kortmann, Bernd 2005. A Comparative Grammar of British English Dialects: Agreement, Gender, Relative Clauses. Berlin: Mouton de Gruyter.

Legassick, Martin 2010. The Struggle for the Eastern Cape: Subjugation and the Roots of South African Democracy. Johannesburg: KMM Review.

Lehmann, Christian 1985. Grammaticalization: Synchronic Variation and Diachronic Change. Lingua e Stile 20: 303 -318.

Lewis, M. Paul, Gary F. Simons \& Charles D. Fennig 2014. Ethnologue: Languages of the World. Dallas: SIL International. (17th edn.) Online version: <ethnologue.com>, accessed 11 Apr. 2015.

Louw, Jacobus A. \& J.B. JubASE 1963. Handboek van Xhosa. Johannesburg: Bonapers Beperk.

LÜPKE, Friederike 2015. Ideologies and Typologies of Language Endangerment in Africa. In: J. Essegbey, B. Henderson \& F. Mc Laughlin (eds): 59-106.

McLaren, James 1944. A Xhosa Grammar. London: Longmans, Green \& Co.

Maно, Jouni F. 2003. A Classification of the Bantu Languages: An Update of Guthrie's Referential System. In: D. Nurse \& G. Philippson (eds): 639-651.

Maно, Jouni F. 2009. NUGL Online: The Online Version of the New Updated Guthrie List, A Referential Classification of the Bantu Languages.

Marten, Lutz, Hannah Gibson, Rozenn Guérois \& Eva-Marie Bloom Ström in press. Morphosyntactic Variation in Bantu: An Introduction. In: E.-M. Bloom Ström, H. Gibson, R. GuÉrois \& L. Marten (eds), Approaches to Morphosyntactic Variation in Bantu. Oxford: OUP.

Marten, Lutz, Nancy C. Kula \& Nhlanhla Thwala 2007. Parameters of Morphosyntactic Variation in Bantu. Transactions of the Philological Society 105: 1-86.

Marten, Lutz \& Malin Petzell 2016. Linguistic Variation and the Dynamics of Language Documentation: Editing in 'pure' Kagulu. In: M. SEYFeddinipur (ed.), African Language Documentation: New Data, Methods and Approaches: 105-129. Honolulu: University of Hawai'i Press. 
MARTEn, Lutz \& Jenneke VAN DER WAL 2014. A Typology of Bantu Subject Inversion. Linguistic Variation 14: 318-68.

Matthewson, Lisa 2004. On the Methodology of Semantic Fieldwork. International Journal of American Linguistics 70: 369-415.

Mbadi, Lucas M. 1956. Some Phonological and Morphological Differences between Xhosa and Mpondomise. BA Honours thesis, University of Cape Town.

Mithun, Marianne 1998. The Significance of Diversity in Language Endangerment and Preservation. In: L.A. Grenoble \& L.J. Whaley (eds), Endangered Languages: Language Loss and Community Response: 163-191. Cambridge: CUP.

Mithun, Marianne 2001. Who Shapes the Record: The Speaker and the Linguist. In: P. Newman \& M. RatLiff (eds): $34-54$.

MLETshe, Loyiso 2017. Deverbal Nominals Derived from Intransitive State Verbs in IsiXhosa: A Generative Lexicon Approach. South African Journal of African Languages 37: 29-39.

Mosel, Ulrike 2006. Fieldwork and Community Language Work. In: J. GipPert, N.P. Himmelmann \& U. Mosel (eds): $67-85$.

Mosel, Ulrike 2011. Morphosyntactic Analysis in the Field: A Guide to the Guides. In: N. Thieberger (ed.), The Oxford Handbook of Linguistic Fieldwork. Oxford: OUP.

Mosel, Ulrike 2012. Creating Educational Materials in Language Documentation Projects: Creating Innovative Resources for Linguistic Research. In: F. Seifart, G. Haig, N.P. Himmelmann, D. Jung, A. Margetts \& P. Trilsbeek (eds): Potentials of Language Documentation: Methods, Analyses, and Utilization: 111-117. Honolulu: University of Hawai'i Press.

Msimang, Christian T. 1989. Some Phonological Aspects of the Tekela-Nguni Dialects. Doctoral dissertation, University of South Africa.

Nathan, David 2011. Digital Archiving. In: P.K. Austin \& J. Sallabank (eds): 255-273.

Newman, Paul \& Martha S. Ratliff (eds) 2001. Linguistic Fieldwork. Cambridge: CUP.

Nomlomo, Vuyokazi S. 1993. Language Variation in the Transkeian Xhosa Speech Community and Its Impact on Children's Education. Cape Town: University of Cape Town.

Nordhoff, Sebastian, Harald Hammarström, Robert Forkel \& Martin Haspelmath 2013. Glottolog 2.2. Leipzig: Max Planck Institute for Evolutionary Anthropology.

NurSe, Derek 2008. Tense and Aspect in Bantu. NY: OUP.

Nurse, Derek \& Gérard Philippson (eds) 2003. The Bantu Languages. London: Routledge.

Nyamende, Abner 1994. Regional Variation in Xhosa. Stellenbosch Papers in Linguistics Plus 26: 202-217.

Oosthuysen, Jacobus C. 2016. The Grammar of IsiXhosa. Stellenbosch: SUN MeDIA.

PAHL, Herbert W. 1983. IsiXhosa. Johannesburg: Educum Publishers. (3rd edn, 4th impression)

Pahl, Herbert W., A.M. PIEnaAR \& T.A. Ndungane 1989. The Greater Dictionary of Xhosa, III, Q-Z. Alice: University of Fort Hare.

Pahl, Herbert W., A.M. Pienaar, T.A. Ndungane, B.M Mini, S.L. Tshabe, F.M. Shoba \& P.N. van der Westhuzien 1989-2006. The Greater Dictionary of IsiXhosa, I-III. Alice: University of Fort Hare.

Peires, Jeffrey B. 1982. The House of Phalo: A History of the Xhosa People in the Days of Their Independence. Berkeley: UC Press.

Petzell, Malin in press. An Analysis of the Verbal Particle tsa in Luguru. In: M. Petzell, L. Bar-el \& L. Aunio (eds), The Semantics of Verbal Morphology in Under-Described Languages. (Special Issue of Studia Orientalia Electronica).

Petzell, Malin \& Harald Hammarström 2013. Grammatical and Lexical Comparison of the Greater Ruvu Bantu Languages. Nordic Journal of African Studies 22: 129-157.

Phoоfolo, Pule 2005. Female Extramarital Relationships and their Regulation in Early Colonial Thembuland, South Africa, 1875-95. Journal of Family History 30: 3-47.

Du Plessis, Jacobus A. \& Marianna W. VISSER 1992. Xhosa Syntax. Johannesburg: Afrikaanse Pers-Boekhandel.

Poletto, Cecilia \& Paola Benincì 2007. The ASIS Enterprise: A View on the Construction of a Syntactic Atlas for the Northern Italian Dialects. Nordlyd 34: 35-52.

Poulos, George \& Christian T. Msimang 1998. A Linguistic Analysis of Zulu. Cape Town: Via Afrika. 
Reagan, Timothy G. 1987. The Politics of Linguistic Apartheid: Language Policies in Black Education in South Africa. The Journal of Negro Education 56: 299-312.

Reppen, Randi, Susan M. Fitzmaurice \& Douglas Biber 2002. Using Corpora to Explore Linguistic Variation. Amsterdam: John Benjamins.

SAvić, Stefan 2017. The Perfective and Imperfective Aspects in Xhosa. Stellenbosch Papers in Linguistics Plus 52: 45-72. Schultze-Berndt, Eva 2006. Linguistic Annotation. In: J. Gippert, N.P. Himmelmann \& U. Mosel (eds): $213-251$.

Skopeteas, Stavros, Ines Fiedler, Sam Hellmuth, Anne Schwarz, Ruben Stoel, Gisbert Fanselow, Caroline Féry \& Manfred KRIFKA (eds) 2006. Questionnaire on Information Structure (QUIS): Reference Manual. (Working Papers of the SFB 632 4) Potsdam: Universitätsverlag Potsdam.

Slabbert, Sarah \& Rosalie Finlayson 1998. Comparing Nguni and Sotho: A Sociolinguistic Classification. In: I. Maddieson \& T.J. Hinnebusch (eds), Language History and Linguistic Description in Africa: 289-306. Asmara: Africa World Press.

SogA, J. Henderson 1930. The South-Eastern Bantu (Abe-Nguni, aba-Mbo, ama-Lala). Johannesburg: Witwatersrand University Press.

VAN DER Spuy, Andrew 1993. Dislocated Noun Phrases in Nguni. Lingua 90: 335-355.

Stapleton, Timothy 1996. The Expansion of a Pseudo-Ethnicity in the Eastern Cape: Reconsidering the Fingo "Exodus" of 1865. The International Journal of African Historical Studies 29: 233-250.

Ström, Eva-Marie 2009. The Situation of Ndengeleko: A Coastal Tanzanian Language (P10). In: M. Matondo, F.M. Laughlin \& E. Potsdam (eds), Selected Proceedings of the 38th Annual Conference on African Linguistics: 229-241. Somerville: Cascadilla Proceedings Project.

THIPA, Henry Mothebesoane 1989. The Difference between Rural and Urban Xhosa Varieties: A Sociolinguistic Study. Doctoral dissertation, University of Natal.

Tyabashe, Mdukiswa 2006. The Origin and History of the Mpondomise People. In: N. Bhotomane, U. Biyela, M. Koko, A. Ngcama, S. Ngcobo, M. Tyabashe \& N.M. Zenani (eds), South African Voices: The Way We Travelled: Oral History and Poetry. Madison: Parallel Press.

de Vos, Mark \& Kristin van der Merwe 2014. The Postgraduate Strategic Early Literacy Imperative: Linguistic and Social Partnerships in Foundation-Phase Learning in African Languages. <https://www.ru.ac.za/ englishlanguageandlinguistics/research/sandisaimbewu/>, accessed 29 Apr. 2015.

VAN DER WAL, Jenneke 2017. What is the Conjoint/Disjoint Alternation? Parameters of Crosslinguistic Variation. In: J. VAN DER WAL \& L.M. HYMAN (eds): 14-60.

VAN DER WAL, Jenneke \& Larry M. HyMAn 2017. The Conjoint/Disjoint Alternation in Bantu. Berlin: De Gruyter.

Woodbury, Anthony C. 2005. Ancestral Languages and (Imagined) Creolisation. In: P.K. Austin (ed.), Language Documentation and Description: 252-262. London: SOAS.

ZanUtTini, Raffaella \& Laurence Horn (eds) 2014. Micro-Syntactic Variation in North American English. Oxford: OUP.

Zeller, Jochen 2004. Relative Clause Formation in the Bantu Languages of South Africa. Southern African Linguistics and Applied Language Studies 22: 75-93.

Zungu, Elphas 1999. A Comparative Phonological and Morphological Analysis of the North and South Lala Dialects of Tekela Nguni. Doctoral dissertation, University of South Africa.

Zungu, P.J.N. 1989. Ntlangwini, a Tekela-Nguni Dialect and Its Relationship to Standard Zulu. MA thesis, University of Natal. 